MODELING, IDEN'TIFICATION AND CONTROL, 1998, VOL. 19, NO. 1, 31-59

doi:10.4173/mic.1998.1.3

\title{
On the $\mathrm{AlF}_{3}$ and temperature control of an aluminum electrolysis cell
}

\author{
TORMOD DRENGSTIG $\uparrow$, DAG LJUNGQUIST $\$$ and BJARNE A. FOSS*
}

Keywords: modeling, metals industry, temperature control, electrochemical processes, $\mathrm{AlF}_{3}$ control

\begin{abstract}
In this paper we propose a control strategy for excess $\mathrm{AlF}_{3}$ and bath temperature of a prebakc aluminum electrolysis cell based on analyzes of measured data and studies of a simple dynamic model. Model validation indicates that there are dynamics that the model does not capture, and hence, we use real data of excess $\mathrm{AlF}_{3}$ and bath temperature to estimate $\mathrm{AlF}_{3}$ and energy disturbances respectively. The estimation results show that the energy disturbance is the dominating disturbance. Hence, the proposed control strategy is based on an almost constant $\mathrm{AlF}_{3}$ input close to average consumption and energy manipulations to compensate for the disturbances. This requires the possibility for the resistance reference to be reduced without decreasing the current efficiency. Compared to present control strategies, this introduces an additional degree of freedom in the controller. The proposed control strategy may imply a significant economic potential through increased and stabilized current efficiency. reduced and stabilized energy consumption, reduced consumption of expensive additives and prolongation of cell
life.
\end{abstract}

\section{Introduction}

The issue of $\mathrm{AlF}_{3}$ and temperature control has been intensively discussed in the aluminum community for the last decade. Focus has been on understanding the $\mathrm{AlF}_{3}$ dynamics in industrial cells. In industry time delays from $\mathrm{AlF}_{3}$ additions to observed response in excess $\mathrm{AlF}_{3}{ }_{3}$ is often experienced. The reason for this delay is not fully understood, though Entner [2] suggested a model where the sodium and fluoride containing compounds are deposited in the cathode. This could in effect be the same as having a sludge phase on the cathode. The model is used in a control strategy for $\mathrm{AlF}_{3}$, and it is further developed in [3]. However, the bath temperature fluctuations using the $\mathrm{AlF}_{3}$ controller were not reduced significantly, and hence, Entner [4] developed a control scheme for both excess $\mathrm{AlF}_{3}$ and bath temperature. This is further refined by Entner and Gudmundson [5].

Based on the observed correlation between bath temperature and excess $\mathrm{AlF}_{3}$, Desclaux [6] compares two control strategies, i.e. $\mathrm{AlF}_{3}$ additions based on 1) bath composition analyzes and 2) temperature measurements. The conclusion is that both control practices are equivalent, though temperature measurements are easier, faster and

Received 10 October 1997.

*Author to whom correspondence should be addressed.E-mail: Bjarne.Foss@itk.ntnu.no. The authors are with the Department of Engineering Cybernetics, Norwegian University of Science and Technology, N-7034 Trondheim, Norway.

'From [1], excess $\mathrm{AlF}_{3}$ is defined as the ratio of $\mathrm{AlF}_{3}$ to $\mathrm{Na}_{3} \mathrm{AlF}_{6}$. In this paper we define excess $\mathrm{AlF}_{3}$ as the mass fraction of $\mathrm{AlF}_{3}$.

(c) 1998 IEEE. To appear in IEEE Transactions on Control System Technology, Vol. 6, 1998. Norway.

\$Elkern Research, P.O. Box 8040, Vågsbygd 4602 Kristiansand. Norway. 
more precise than the bath composition analyzes. However, the success of this control strategy is dependent on a fast equilibrium between bath composition and temperature. Wilson [7] have developed and implemented a control strategy where $\mathrm{AlF}_{3}$ additions are based on bath temperature and cell age only. The performance is reported to be good, handling a range of operational changes, i.e. it is not restricted to stable conditions as reported in [6].

In addition to bath composition analyzes, bath temperature and cell age, other cell variables and parameters can be used in the $\mathrm{AlF}_{3}$ control strategy. Peyneau [8] describes a control strategy developed by Aluminium Pechiney using up to 8 different cell parameters for bath composition control, with the energy induced by anode effects being the most important additional parameter.

It is known that the energy balance, in addition to $\mathrm{AlF}_{3}$ additions, also affects the excess $\mathrm{AlF}_{3}$ through the interaction with the side ledge. In order to investigate the effect of the energy balance on the excess $\mathrm{AlF}_{3}$, Taylor [9] performed a simple input/output calculation of $\mathrm{AlF}_{3}$ and showed that the changes in the mass balance for $\mathrm{AlF}_{3}$ can not explain the observed changes in excess $\mathrm{AlF}_{3}$. Hence, the energy balance is more important than previously expected. Common for the contributions discussed above is the lack of explanation to the underlying cause of the experienced cell behavior.

Very few contributions have focused on dynamic simulation of an aluminum electrolysis cell. In [10] a dynamic mass and energy balance model of 11 chemical species is presented. The model is simulated and verified against temperature, alumina concentration and excess $\mathrm{AlF}_{3}$. This model is not used for control purposes.

The number of publications focusing on $\mathrm{AlF}_{3}$ and temperature control found in the open literature is small compared to the number of contributions on other topics of the aluminum electrolysis process. Due to lack of basic understanding of the $\mathrm{AlF}_{3}$ variations, present control algorithms are based on analysis of historical data and practical experience. Despite new and improved control strategies, the fluctuations in the excess $\mathrm{AlF}_{3}$ are considered high in most cell lines. Hence, our motivation for focusing on $\mathrm{AlF}_{3}$ and temperature dynamics is primarily to gain insight into the phenomena of the process, and secondly to use this knowledge to improve cell control. This again may result in increased current efficiency and reduced energy consumption.

The outline of the paper is as follows. In Sec. II a brief process description is given and in Sec. III we refine the problem statement. Further, in Sec. IV, we employ a modeling methodology described in the Appendix to develop and represent a mathematical model. The model is validated against known behavior and real data in Sec. $\mathrm{V}$. Based on the validation result, estimation of equivalent $\mathrm{AlF}_{3}$ and energy disturbances is performed in Sec. VI. Finally, we suggest a novel control strategy and give concluding remarks in Secs. VII and VIII respectively.

\section{Process description}

The Hall-Héroult process is dominating worldwide in the production of aluminum [1]. The fundamentals of the process are to dissolve $\mathrm{Al}_{2} \mathrm{O}_{3}$ in molten cryolite, and electrically reduce complex aluminum containing ions to pure aluminum. The overall electro-chemical reaction in the electrolyte is

$$
2 \mathrm{Al}_{2} \mathrm{O}_{3}+3 \mathrm{C} \rightarrow 4 \mathrm{Al}+3 \mathrm{CO}_{2}
$$

where carbon is fed to the reaction as consumable anodes. By the use of various additives like $\mathrm{AlF}_{3}$ and $\mathrm{CaF}_{2}$, the operating temperature of the electrolyte can be lowered from $1010^{\circ} \mathrm{C}$ to approximately $960^{\circ} \mathrm{C}$. Both decreased temperature and increased 


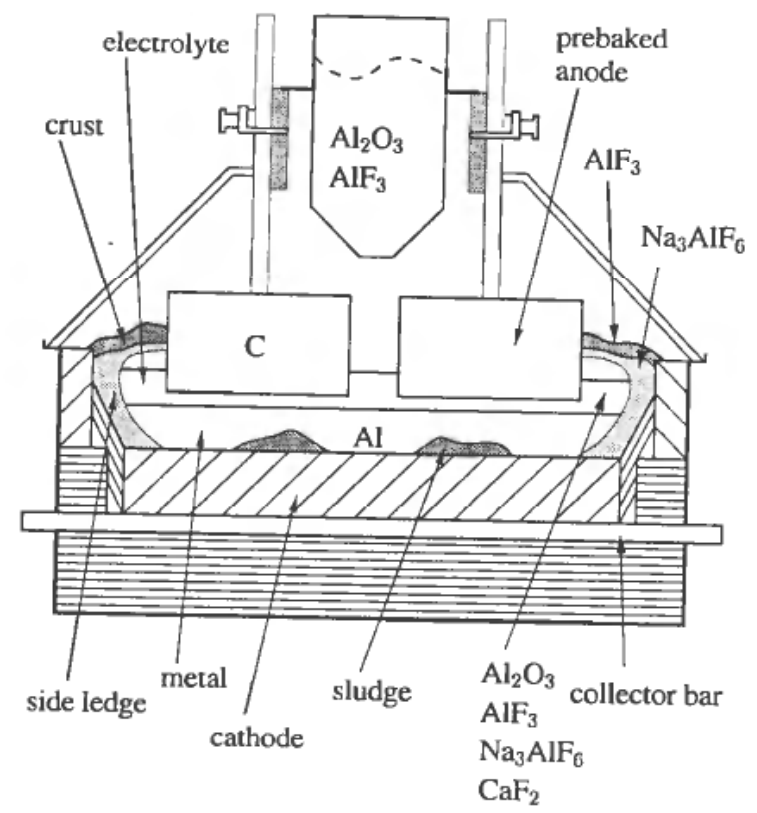

Figure 1. Prebake anode cell.

excess $\mathrm{AlF}_{3}$ is believed to be beneficial for the current efficiency and the energy consumption. However, fluoride evaporates and $\mathrm{AlF}_{3}$ must therefore be added regularly. There are basically two types of cells used in industry; the so-called prebake and Söderberg cells, where the main difference is the anode arrangement. A schematic sketch of a prebake cell considered in this paper is shown in Fig. 1.

As molten cryolite is very corrosive, the only component of an acceptable cost presently capable of coexisting with it over time is frozen cryolite. It is therefore necessary to maintain a layer of frozen cryolite (side ledge) to prevent the carbon walls from eroding. According to the phase diagram this side ledge consists of cryolite only, and moreover, it acts as a buffer for both increase and decrease in bath temperature through melting and freezing. A top layer of frozen bath (crust) will also be formed during operation. This crust reduces heat loss from bath and protects the anodes from combustion. In order to maintain the side ledge there has to be a substantial heat loss through the side ledge and the carbon walls of the cell. The cell voltage applied is typically $4.5 \mathrm{~V}$, and the electric current through the cell is typically $150-200 \mathrm{kA}$.

\section{Problem statement}

In order to reduce energy consumption, minimize the use of expensive additions like $\mathrm{AlF}_{3}$ and $\mathrm{Na}_{2} \mathrm{CO}_{3}$ used in present control practices and prolong cell life, the aim of the aluminum industry is to achieve stable cell conditions during normal operation. By the use of an alumina controller to control the alumina concentration and anode beam movements to keep the measured resistance at a reference level, this is only partially achieved. Due to the lack of continuous measurements, direct or indirect, of excess $\mathrm{AlF}_{3}$, the level is determined by time-consuming sample preparation and chemical analyzes. The excess $\mathrm{AlF}_{3}$ is not only dependent on the amount of $\mathrm{AlF}_{3}$ in the bath, but also on the amount of all other compounds, and especially $\mathrm{Na}_{3} \mathrm{AlF}_{6}$ frozen and melted according to the energy balance of the cell. Hence, the control of excess 


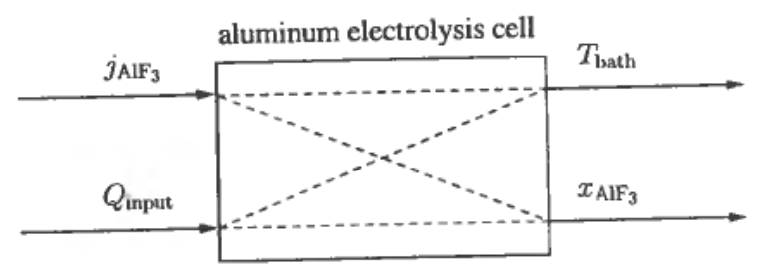

Figure 2. Visualization of the highly interactive aluminum cell.

$\mathrm{AlF}_{3}$ becomes a highly interactive multi-variable control problem. This is illustrated in Fig. 2.

The control inputs are $\mathrm{AlF}_{3}$ additions, $j_{\mathrm{AIF}_{3}}$, and resistive energy generated in the bath, $Q_{\text {input }}=R_{\text {bath }} \cdot I_{\text {cell. }}^{2}$ The outputs are excess $\mathrm{AlF}_{3}, x_{\mathrm{AlF}_{3}}$, and bath temperature, $T_{\text {bath }}$. Other aspects having impact on the control problem is the lack of detailed information of the fluoride and sodium content in alumina, the sodium ( $\mathrm{Na}$ ) consumption of the cathode, the amount of fluroride evaporating from the bath and the amount of $\mathrm{AlF}_{3}$ in side ledge and sludge. Moreover, variations in heat loss from bath, variations in current efficiency, creation and deformation of crust, anode changing, and tapping of metal and bath also have impact on the control problem.

From industrial cells it is experienced that bath temperature and excess $\mathrm{AlF}_{3}$ has an unpredictable behavior in that sudden changes occur, even if the preceding $\mathrm{AlF}_{3}$ additions have been close to the average consumption. When the excess $\mathrm{AlF}_{3}$ is low and the bath temperature is high, the corrective action is usually to add more $\mathrm{AlF}_{3}$. However, the expected increase in excess $\mathrm{AlF}_{3}$ is often delayed several days, and more $\mathrm{AlF}_{3}$ is added. This over-compensation result in oscillations in excess $\mathrm{AlF}_{3}$, which is detrimental from both operational and economic points of view.

The question is then whether 1) there is a transport delay from addition to dissolution of $\mathrm{AlF}_{3}$ which consequently cause the drop in temperature (due to lowered liquidus temperature and increased side ledge melting), or 2) the increase in excess $\mathrm{AlF}_{3}$ is due to freezing of bath as the temperature drops. It is a question of cause and effect within the cell. In this paper we try to identify this cause and effect relationship, and use the result to formulate a control strategy.

\section{Model development}

In order to develop consistent mathematical models and validate the assumptions used, it is often of crucial importance for the modeler to obtain a fruitful discussion with different process domain experts. In many cases, the best way to support this communication is to represent the model graphically in some sense [11]. Hence, we have defined and formalized a graphical representation scheme [12], and used it for model development. The graphical scheme is based on a formal representation of physical phenomena of chemical processes. Due to the modularization principle used, the methodology has proven to be efficient for model building and enhancement. This is a valuable property in validating different model hypotheses.

In [12] it is argued that a separation of the representation into a mass and an energy aspect is favorable. For the aluminum electrolysis cell, this approach is very useful in that it demonstrates that the mass and energy aspects are different since they focus on different phenomena of the process. A PTD (process topology diagram) is a diagram where the topological part of the model is represented. The phenomenological part of 
the model is represented in a TRAV (transport, reaction and accumulation view). The main symbol notation for the methodology is given in the Appendix.

In order to illustrate the variety of models considered in this work and to introduce and elucidate the use of the modeling methodology, we will in Sec. B develop a rather complex model based on Fig. 1 and the assumptions given in Sec. A. The relation between symbols and equations will also be illustrated in Sec. B.

\section{A. Model assumptions}

The following assumptions are chosen for the models presented in this paper.

- In industry it is found that the side ledge contains both $\mathrm{AlF}_{3}$ and $\mathrm{Al}_{2} \mathrm{O}_{3}$ in addition to $\mathrm{Na}_{3} \mathrm{AlF}_{6}$, mainly due to rapid freezing and melting of side ledge. However, for the purpose of our model, it is assumed that the side ledge consists of $\mathrm{Na}_{3} \mathrm{AlF}_{6}$ only.

- The metal circulations induce stirring of the bath. Hence, the bath is assumed to be ideally mixed (CSTR).

- The heat transfer coefficient between bath and side ledge is found to vary between 500 and $1000 \mathrm{~J} \mathrm{~K}^{-1} \mathrm{~s}^{-1} \mathrm{~m}^{-2}$ [1]. However, we assume it to be constant.

- The fluoride and sodium content in the secondary alumina is assumed to be constant.

- The energy effect of anode changes is not included. This is due to the lack of knowledge regarding heat loss from bath to surroundings.

- Effects of metal and bath tapping are neglected.

- The contact area between bath and side ledge and the side ledge profile are assumed constant.

Based on these assumptions, we can exemplify the use of the modeling methodology on Fig. 1.

\section{B. Representation of a comprehensive model}

The mass and energy aspect of this model is shown in Figs. 3 and 4 . The model takes sludge formation and dissolution into account, and the similarities to Fig. 1 should be apparent. We identify the main chemical phases and species existing in the cell cavity.

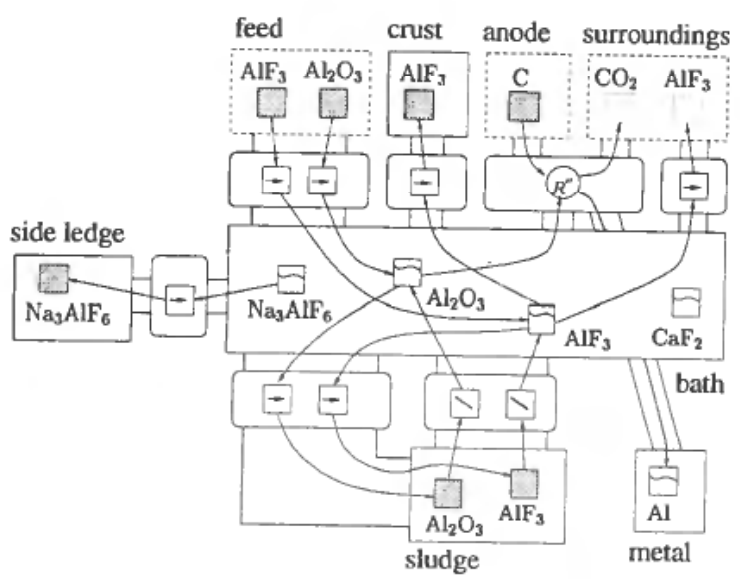

Figure 3. PTD and TRAV for the aluminum electrolysis cell, mass aspect. 


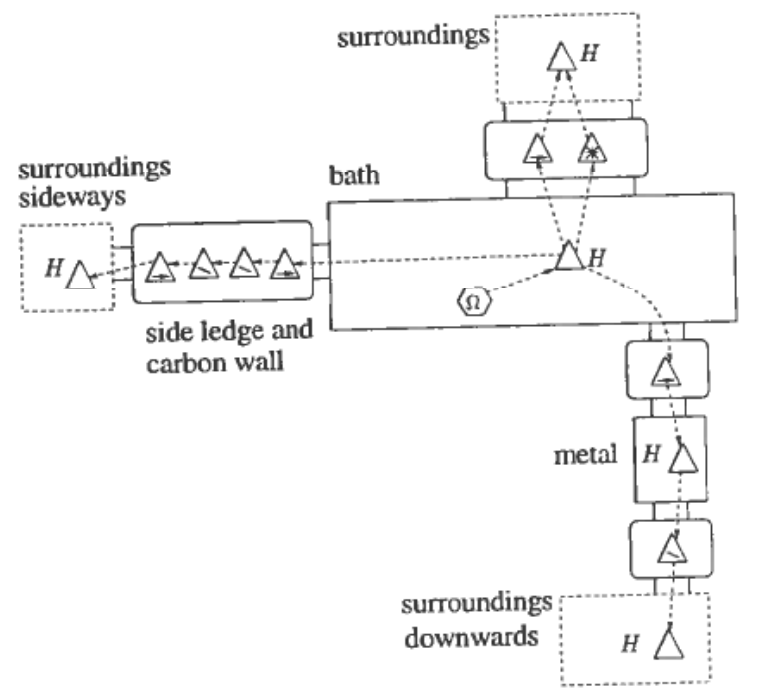

Figure 4. PTD and TRAV for the aluminum electrolysis cell, energy aspect.

The representation immediately reveals that the bath interacts with the side ledge through a flow of $\mathrm{Na}_{3} \mathrm{Al}$ to $\mathrm{F}_{6}$, and that the side ledge is assumed to consist of solid $\mathrm{Na}_{3} \mathrm{AlF}_{6}$ only. This corresponds the assumption made. The total number of dynamic states are 11. The mass accumulation symbols in the feed, anode and surroundings devices in Fig. 3 are sinks and sources, implying that they are not dynamic states. This is also the case for the energy accumulation symbols in the surroundings, surroundings sideways and surroundings downwards devices in Fig. 4.

In order to be useful for model development, the phenomenological symbols in Figs. 3 and 4 must be related to equations. This must be a one-to-one relationship in order to be consistent, and the representation is a visualization of the mathematical model of the process. If we study the structure of a general balance equation, it can be written as

rate of change in holdup $=$ rate of exchange + rate of generation/consumption,

where the exchange term comprises all the inlet and outlet flows and the generation/consumption comprises the appearing or disappearing of chemical species or energy within the system boundaries. Viewing this balance equation together with the structure of symbols and relations in Figs. 3 and 4, we see that, e.g. the $\mathrm{Al}_{2} \mathrm{O}_{3}$ accumulation symbol $\boxminus$ have inputs, outputs and consumption flow lines attached to it. Hence, the underlying balance equation can be read out of Fig. 3 as

$$
\frac{d n_{\mathrm{Al}_{2} \mathrm{O}_{3}}}{d \mathrm{t}}=j_{\mathrm{Al}_{2} \mathrm{O}_{3} \text {,(feed } \rightarrow \text { bath) }}+j_{\mathrm{Al}_{2} \mathrm{O}_{3} \text {,(sludge } \rightarrow \text { bath) }}-j_{\mathrm{Al}_{2} \mathrm{O}_{3} \text {, (bath } \rightarrow \text { sludge) }}-r_{\mathrm{Al}_{2} \mathrm{O}_{3}} \text {, }
$$

where the syntax (feed $\rightarrow$ bath) means transport direction. The transport symbol of, e.g. the heat convection from bath to metal, $\triangle$, in Fig. 4 is similarly related to an algebraic equation. This implies that the complete model equation structure can be read directly from Figs. 3 and 4, and this representation supports the communication with other resource personnel compared to using detailed and complex equations. However, when it comes to discussion of details in the underlying algebraic equations, e.g. liquidus temperature equation, we still need the equations. 


\section{Specification of algebraic equations}

In this section we will describe the main algebraic equations since these details are not revealed from Figs. 3 and 4.

\section{Liquidus temperature}

The liquidus temperature equation employed here is taken from [1], though the terms comprising $\mathrm{LiF}$ are neglected. Hence, we have

$$
\begin{aligned}
T_{\text {liq }}= & T_{\text {liq } 0}+a_{1} \cdot\left(100 \cdot x_{\mathrm{Al}_{2} \mathrm{O}_{3}}\right)+a_{2} \cdot\left(100 \cdot x_{\left.\mathrm{Al}_{2} \mathrm{O}_{3}\right)}\right)^{1 \cdot 2} \\
& +a_{3} \cdot\left(100 \cdot x_{\mathrm{AlF}_{3}}\right)+a_{4} \cdot\left(100 \cdot x_{\mathrm{AlF}_{3}}\right)^{2 \cdot 5}+a_{5} \cdot\left(100 \cdot x_{\mathrm{AlF}_{3}}\right)^{3} \\
& +a_{6} \cdot\left(100 \cdot x_{\mathrm{AlF}_{3}} \cdot 100 \cdot x_{\mathrm{CaF}_{2}}\right)^{0.7} \\
& +a_{7} \cdot\left(100 \cdot x_{\mathrm{CaF}_{2}}\right)+a_{8} \cdot\left(100 \cdot x_{\mathrm{CaF}_{2}}\right) .
\end{aligned}
$$

\section{Current efficiency}

The current efficiency $\mathscr{C} \mathscr{E}$ is given as

$$
\mathscr{C} \mathscr{E}=f\left(T_{\text {bath }}, x_{\mathrm{AlF}_{3}}\right),
$$

which is based on the work in [13].

\section{Equivalent $\mathrm{AlF}_{3}$ evaporation}

The evaporation of fluoride is modeled as an equivalent $\mathrm{AlF}_{3}$ evaporation, and is given as

$$
j_{\mathrm{AlF}_{3}}=f\left(T_{\text {bath }}, x_{\mathrm{AlF}_{3}}, x_{\mathrm{Al}_{2} \mathrm{O}_{3}}, \mathscr{C} \mathscr{E}\right),
$$

which is a simplified version of Haupins formula [14]. This evaporation model comprises both particulate and gaseous fluoride containing compounds.

\section{Heat loss from bath to surroundings}

The convective heat loss from bath to surroundings, $Q_{\text {conv,loss, }}$ is a function of temperature as

$$
Q_{\text {conv,loss }}=Q_{\text {loss }, 0}+a_{Q \text { loss }}\left(T_{\text {bath }}-T_{\text {bath }, 0}\right) \text {, }
$$

where $T_{\text {bath, } 0}$ and $a_{Q \text { loss }}$ are constants and $Q_{\text {loss }, 0}$ takes into account the heat loss from bath to metal as explained above.

Flow of $\mathrm{Na}_{3} \mathrm{AlF}_{6}$ and energy between bath and side ledge

The flow of $\mathrm{Na}_{3} \mathrm{AlF}_{6}$ between side ledge and bath is determined by the difference in convective heat flow from bath to side ledge and the conductive heat flow through the side ledge, carbon wall and the steel shell. A simplifed sketch of a freezing situation is shown in Fig. 5.

The rate of energy released from molten $\mathrm{Na}_{3} \mathrm{AlF}_{6}$ by freezing is

$$
j_{\mathrm{Na}_{3} \mathrm{AlF}_{6}}\left(\Delta_{\mathrm{fus}_{\mathrm{S}}} H_{\mathrm{Na}_{3} \mathrm{AlF}_{6}}^{\mathrm{o}}+\bar{c}_{p, \mathrm{Na}_{3} \mathrm{AlF}_{6}}\left(T_{\text {bath }}-T_{\text {liq }}\right)\right) \text {. }
$$

It should be noted that this rate of energy is added to the bath at freezing conditions. Moreover, the same rate of energy is required for melting an equal amount of $\mathrm{Na}_{3} \mathrm{AlF}_{6}$, and this energy is then provided by the bath. The flow of $\mathrm{Na}_{3} \mathrm{AlF}_{6}$ between bath and side ledge is then determined by the following equation

$$
j_{\mathrm{Na}_{3} \mathrm{AlF}_{6}}=\frac{Q_{\text {cond }}-Q_{\text {conv }}}{\Delta_{\mathrm{fus}} H_{\mathrm{Na}_{3} \mathrm{AlF}_{6}}^{\mathrm{o}}+\bar{c}_{P, \mathrm{Na}_{3} \mathrm{AlF}_{6}}\left(T_{\text {bath }}-T_{\mathrm{liq}}\right)},
$$




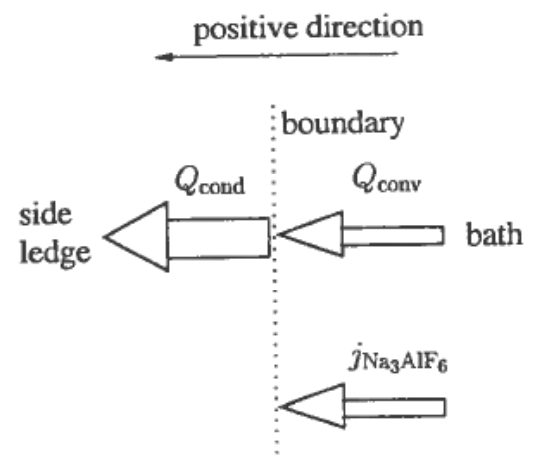

Figure 5. Visualization of freezing of $\mathrm{Na}_{3} \mathrm{AlF}_{6}$.

where

$$
\begin{aligned}
& Q_{\text {cond }}=\frac{A_{\text {bath,ledge }}}{\frac{l_{\text {ledge }}}{k_{\text {ledge }}}+\frac{l_{\text {wall }}}{k_{\text {wall }}}+\frac{1}{h_{\text {stel.lurr }}}}\left(T_{\text {liq }}-T_{0}\right), \\
& Q_{\text {conv }}=h_{\text {bath.ledge }} A_{\text {bart,ledge }}\left(T_{\text {bath }}-T_{\text {liq }}\right) .
\end{aligned}
$$

Note that we use the same area, $A_{\text {bath,ledge }}$, for heat conduction and convection in (9) and (10).

The model in Figs. 3 and 4 using Eqs. (3)-(10) were initially used in the investigation of the cell dynamics. The results from these studies are summarized in the following additional assumptions.

\section{Additional model assumptions}

- It is found that the existence of the liquid aluminum phase has negligible impact on the simulation results. Hence, the heat loss from bath to metal is assumed constant, and added to the convective heat loss from bath to surroundings.

- The use of sludge as a buffer for $\mathrm{AlF}_{3}$ did not improve the simulation results. This is supported by the observation that the delay of $\mathrm{Al}_{2} \mathrm{O}_{3}$ from sludge to bath, which intuitively should be of the same order, is too small compared with the observed delay for $\mathrm{AlF}_{3}$. Moreover, it has been observed that $\mathrm{AlF}_{3}$ dissolves much faster than $\mathrm{Al}_{2} \mathrm{O}_{3}$ in laboratory setups, implying that it should be reasonable to assume that this condition also holds for industrial cells. Hence, $\mathrm{AlF}_{3}$ additions are assumed to dissolve immediately.

- For the problem of $\mathrm{AlF}_{3}$ dynamics, we assume also that $\mathrm{Al}_{2} \mathrm{O}_{3}$ dissolves immediately.

- Sludge phase is not considered.

- Crust/bath interaction is not considered.

- We assume constant current efficiency due to the problem of developing a relationship handling the positive feedback from temperature to current efficiency in a satisfactory manner. Our experience indicates that a current efficiency model should also take average anode-cathode distance into account.

- Heat radiation from bath to surroundings is neglected.

- The temperature profiles through the side ledge, the carbon wall and the outer steel shell are assumed linear, eliminating the need for intermediate temperatures as, e.g. $T_{\text {wall }}$. 


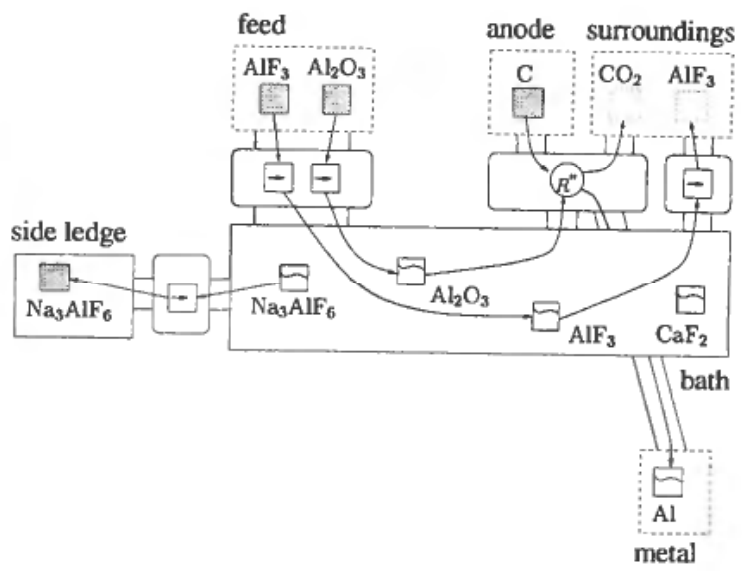

Figure 6. PTD and TRAV for the aluminum electrolysis cell, mass aspect.

As a result of the additional model assumptions, the model is simplified to consist of 5 dynamic states. These are accumulation of $\mathrm{Na}_{3} \mathrm{AlF}_{6}, \mathrm{AlF}_{3}, \mathrm{Al}_{2} \mathrm{O}_{3}$ and energy in bath, and $\mathrm{Na}_{3} \mathrm{AlF}_{6}$ in the side ledge.

\section{E. Simplified model representation}

A simplification of the model in Figs. 3 and 4 is represented in Figs. 6 and 7. This model is used in Secs. V and VI.

The simplified model visualizes the efficiency and usability of the modeling methodology. By removing the sludge, crust and metal devices, we obtain a new representation. The underlying equation structure updates accordingly, and hence, we achieve consistency and save modeling effort.

\section{F. Remarks}

An interesting effect that can be observed is that due to the solid aggregate state of the side ledge, we do not model the energy accumulation, but rather assume a heat flow through the side ledge. Hence, from an energy point of view, the side ledge is a connection. There is however accumulation of $\mathrm{Na}_{3} \mathrm{AlF}_{6}$ in the side ledge, see Fig. 3, implying that from a mass point of view, we consider the side ledge a device. The dependency between the amount of side ledge and the conductive heat flow through the side ledge is given by

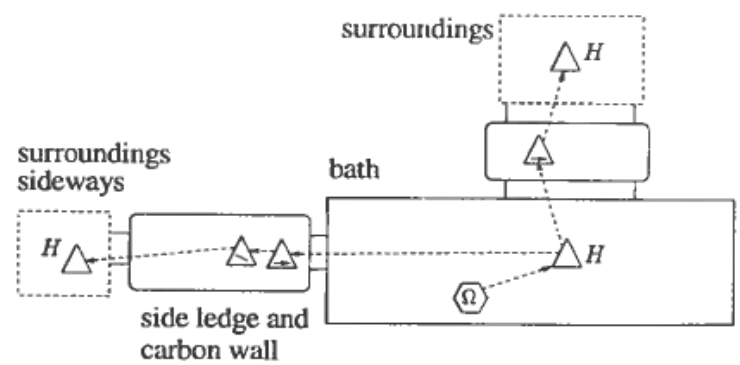

Figure 7. PTD and TRAV for the aluminum electrolysis cell, energy aspect. 


$$
Q_{\text {cond }}=A_{\text {ledge }} \frac{k_{\text {ledge }}}{l_{\text {ledge }}}\left(T_{\text {liq }}-T_{\text {wall }}\right) \text {, }
$$

where $l_{\text {ledge }}$ is determined from the mass balance of the side ledge device.

Note that there is no reduction reaction at the metal surface. The reason is that the overall reaction given in (1) is often satisfactory for a dynamic model of the aluminum cell. This is shown as a reaction occurring at the anode surface, and it exemplifies the level of assumption and simplification we chose prior to the modularization described in the Appendix. The use of (1) implies that a surface reaction has to be moved from one surface to another, in this case from the cathode to the anode, and that the connection between bath and metal is neglected in the mass based topological decomposition. It is however interesting to note that the connection between the bath and metal devices is used when modeling the heat flow in the energy based topological decomposition given in Fig. 4.

\section{Model validation}

In order to investigate whether our model gives intuitive responses with respect to $\mathrm{AlF}_{3}$ addition and energy manipulation, we validate the model responses against known behavior in Sec. A and measurements in Sec. B. For this purpose, the methodology is implemented in Matlab [15] using Simulink [16]. Thermodynamic data of the model are mainly taken from JANAF Thermochemical tables [17]. Moreover, in addition to the inputs shown in Fig. 2, we have the registered $\mathrm{Al}_{2} \mathrm{O}_{3}$ additions.

\section{A. Validation against known behavior using step responses}

We first perform two simple step inputs, i.e. a permanent increase in heat loss of $30 \mathrm{~kJ} \mathrm{~s}^{-1}$ (or a corresponding drop in reference resistance), and a large addition of $\mathrm{AlF}_{3}$ (112 kg over 3 hours). The amount of bath is initially $6700 \mathrm{~kg}$. The addition of $112 \mathrm{~kg}$ $\mathrm{AlF}_{3}$ is rather large, but not unrealistic, compared to additions during normal operation. The step in heat loss should cause the molten $\mathrm{Na}_{3} \mathrm{AlF}_{6}$ in the bath to freeze and release energy according to (7) to the bath, suppressing the impact of the heat loss. This freezing of molten $\mathrm{Na}_{3} \mathrm{AlF}_{6}$ would give an increase in excess $\mathrm{AlF}_{3}$ and an increase in side ledge thickness.

For the $\mathrm{AlF}_{3}$ addition, we would expect an increase in excess $\mathrm{AlF}_{3}$, but not as much as from an isolated bath mass balance, $\left(\frac{112}{6700+112}=0 \cdot 0165\right)$. This is due to the dilution of the bath from melting of side ledge. $\mathrm{As} \mathrm{AlF}_{3}$ is added and dissolved, the liquidus temperature drops, consequently giving an increase in superheat, and thereby melting of side ledge. The simulated responses for bath temperature, excess $\mathrm{AlF}_{3}$ and side ledge are shown in Figs. 8 to 10.

We see that we get intuitive model responses. The resulting increase in excess $\mathrm{AlF}_{3}$ due to $\mathrm{AlF}_{3}$ addition is approximately half of $0 \cdot 0165$. However, the step in heat loss has actually a larger impact on the excess $\mathrm{AlF}_{3}$. The sudden change in excess $\mathrm{AlF}_{3}$ at 8 hours after simulation start, is caused by the assumption of a well mixed situation in the bath. This implies that additions made in the center of the cell has an immediate impact on the side ledge. One way to avoid this immediate and rather unrealistic impact is to divide the cell into e.g. two well mixed zones, one where the feeding is and one in contact with the side ledge. The challenge is then to use reasonable convective and diffusive parameters for heat and mass flow between the zones. This approach is not addressed here.

Note the inverse response of the solid line in Fig. 10. This is due to the addition 
On the $\mathrm{AlF}_{3}$ and temperature control of an aluminum electrolysis cell 41

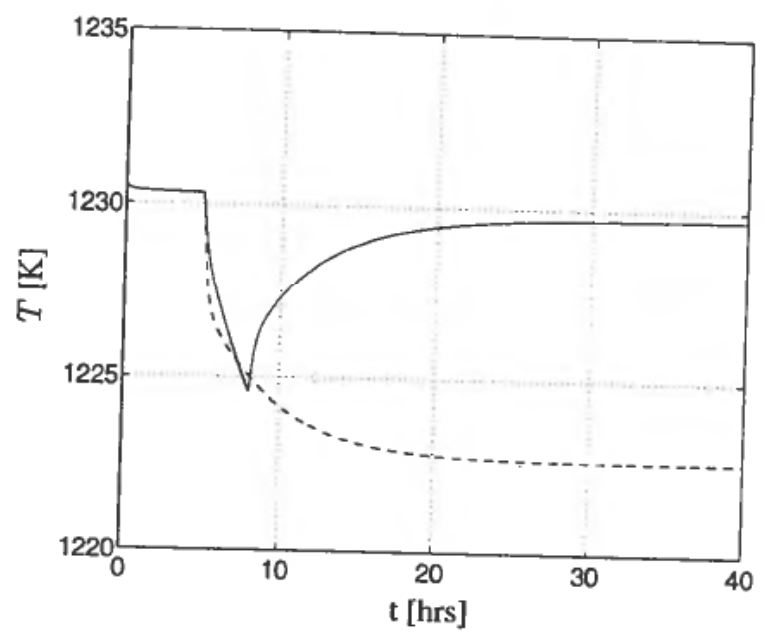

Figure 8. Bath temperature. Solid line: $\mathrm{AlF}_{3}$ addition. Dashed line: Heat loss.

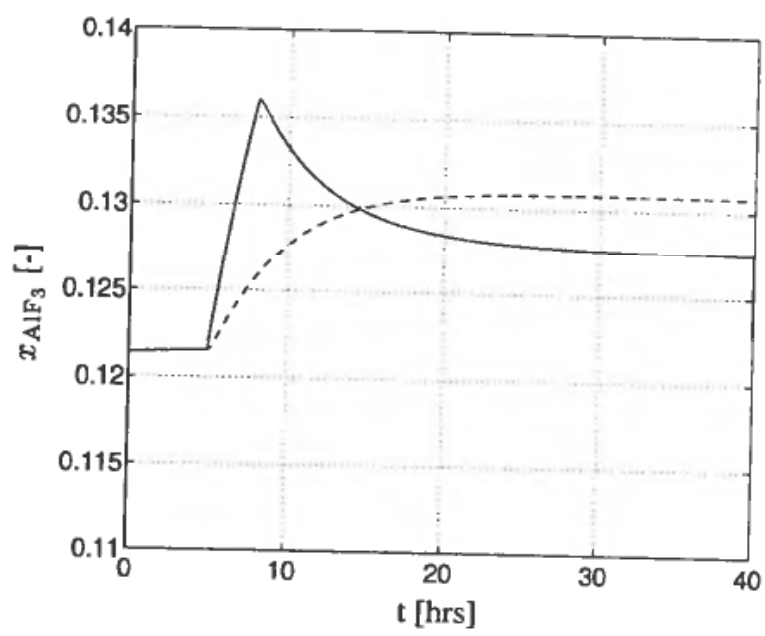

Figure 9. Excess $\mathrm{AlF}_{3}$. Solid line: $\mathrm{AlF}_{3}$ addition. Dashed line: Heat loss.

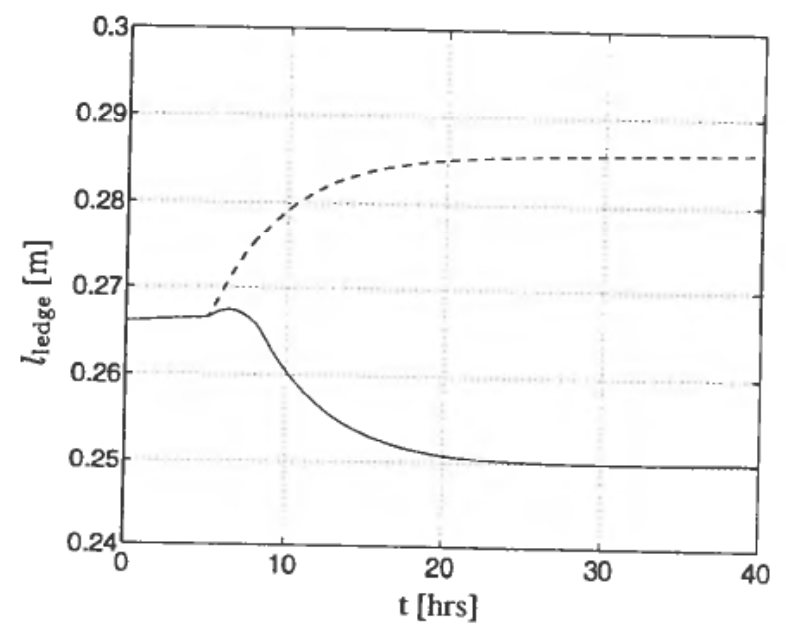

Figure 10. Side ledge thickness. Solid line: $\mathrm{AlF}_{3}$ addition. Dashed line: Heat loss. 
of cold and solid $\mathrm{AlF}_{3}$ and the immediate need for energy for heating and dissolution. The result is freezing of $\mathrm{Na}_{3} \mathrm{AlF}_{6}$, and a temporal increase in side ledge thickness.

In industrial cell lines we often find conditions where increased excess $\mathrm{AlF}_{3}$ corresponds to increased side ledge thickness. From Fig. 10 we can conclude that these variations are caused by variations in the energy balance.

\section{B. Validation against measurements using real input data}

The simulations shown here use the input data of the $\mathrm{AlF}_{3}$ addition and the resisitive energy generated in the bath shown in Figs. 11 and 12. Both input variables are based on the average input every 8 hours. Moreover, the $\mathrm{AlF}_{3}$ addition is the pure $\mathrm{AlF}_{3}$ addition corrected for the fluoride and sodium content in the secondary alumina. The energy induced by anode effects are included in the $Q_{\text {input }}$. The initial amount of bath in these

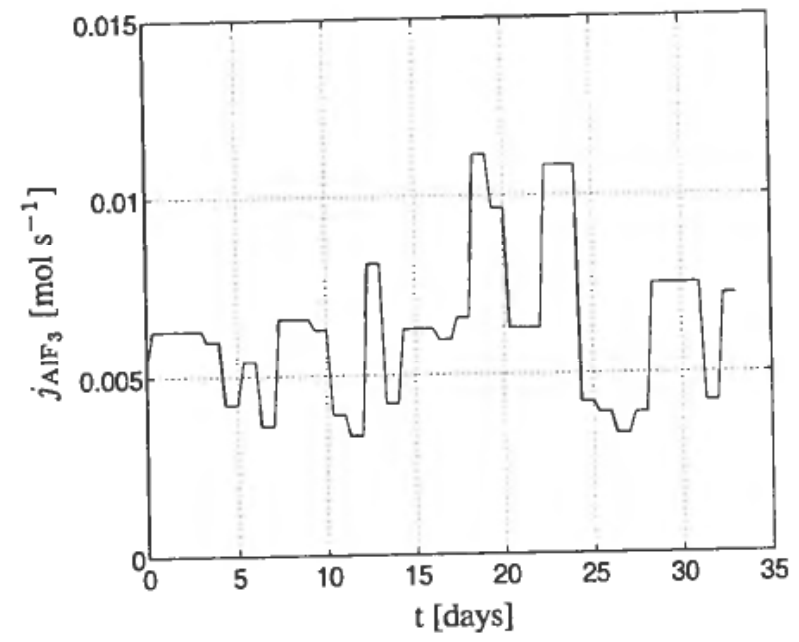

Figure 11. Registered $\mathrm{AlF}_{3}$ input. Note that a rate of $0 \cdot 005 \mathrm{~mol} \mathrm{~s}^{-1}$ is equivalent to $36 \mathrm{~kg} \mathrm{day}^{-1}$.

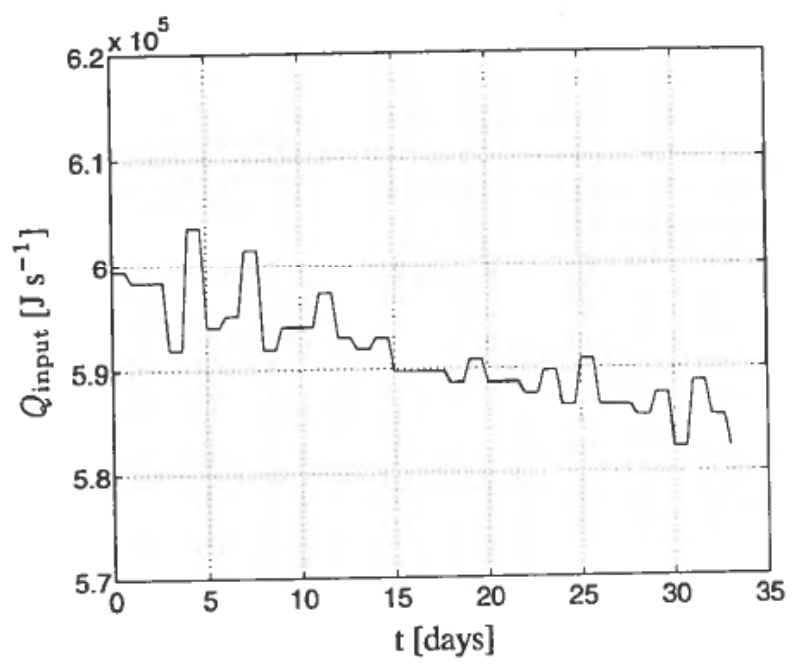

Figure 12. Resistive energy input to bath. 

simulations is $4400 \mathrm{~kg}$. The registered $\mathrm{Al}_{2} \mathrm{O}_{3}$ additions are also used as model input (not
shown).

As indicated in the previous section, the heat loss has a substantial impact on the model behavior, and especially on excess $\mathrm{AlF}_{3}$. Since the data set does not include measurements of the heat loss from bath to the surroundings, we use in this simulation case, Case 1, two heat loss models. That is, in Case 1a we use the relationship given in (6), and in Case $1 \mathrm{~b}$ we use a constant heat loss. The resulting excess $\mathrm{AlF}_{3}$ and temperature responses are shown in Figs. 13 and 14. It should be noted that the number of moles $\mathrm{AlF}_{3}$ in the bath is the same for both simulations.

If we isolate and study the registered $\mathrm{AlF}_{3}$ addition in Fig. 11 and the analyzed excess $\mathrm{AlF}_{3}$ shown in Fig. 13, it suppports the impression of a time delay from the first

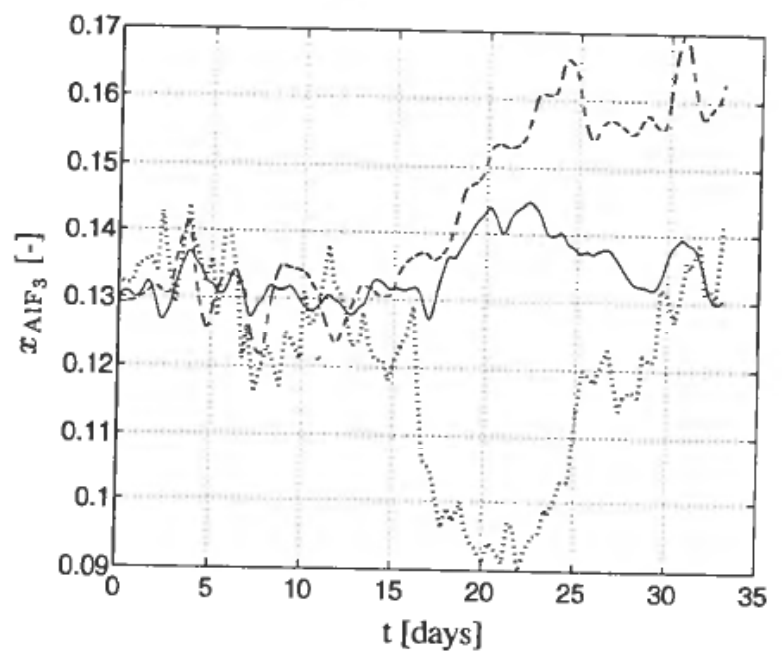

Figure 13. Excess $\mathrm{AlF}_{3}$. Solid line: Case 1a, using varying heat loss. Dashed line: Case 1b, using constant heat loss. Dotted line: Analyzed value.

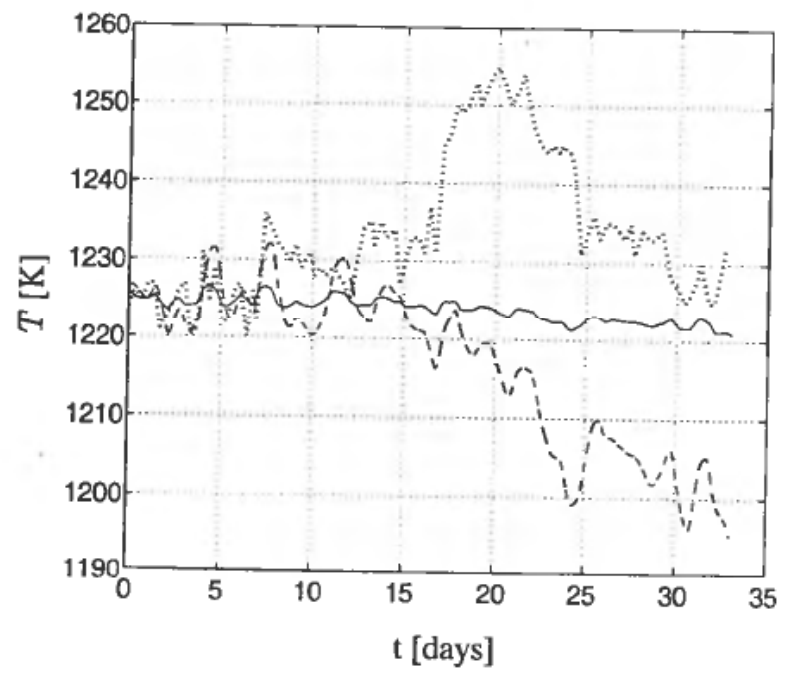

Figure 14. Bath temperature. Solid line: Case 1a, using varying heat loss. Dashed line: Case

1b, using constant heat loss. Dotted line: Measured value. 


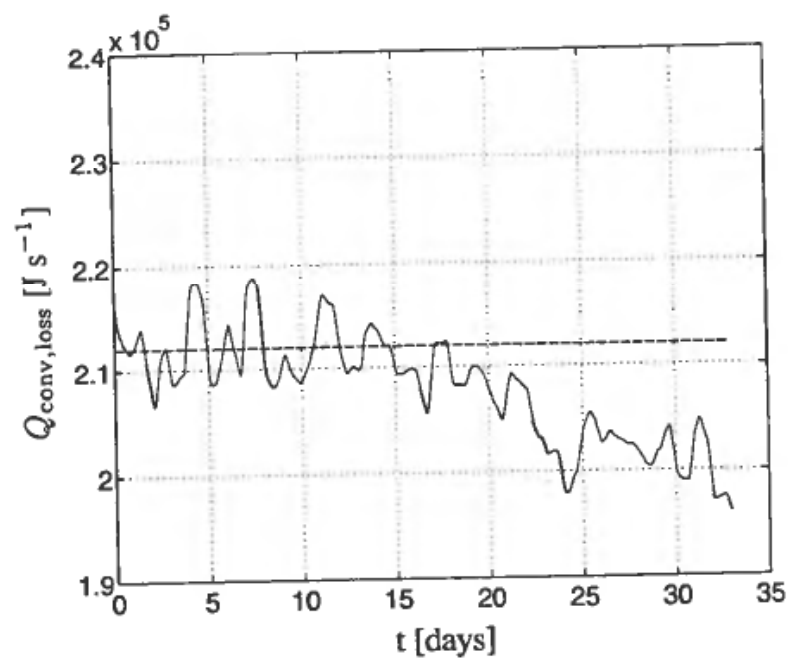

Figure 15. Heat loss from bath to surroundings. Solid line: Case 1a, using varying heat loss. Dashed line: Case 1b, using constant heat loss.

large addition of $\mathrm{AlF}_{3}$ at day 18 to the analyzed response at day 25 . As we can see, the model does not capture this time delay.

The corresponding heat loss for the two cases are given in Fig. 15. As mentioned in Sec. IV-D, the assumed constant heat flow from bath to metal is added to this heat loss.

The simple relationship for the heat loss used in Case 1a leads to a stabilizing effect in bath temperature, see Fig. 14. This can be verified by comparing the energy input $Q_{\text {input }}$, in Fig. 12 with the heat loss, $Q_{\text {conv,loss }}$, in Fig. 15. The variations and trend in $Q_{\text {input }}$ are compensated by similar variations and trend in $Q_{\text {conv.loss, }}$, and hence, the net changes to the energy balance are small.

These simulations show that for the constant heat loss case, the temperature and excess $\mathrm{AlF}_{3}$ show good conformity the first 8 days. However, in the interval from 16 to 33 days it is revealed that there are dynamics that the model structure does not capture. One reason could be that the model structure shown in Figs. 6 and 7 is too simple. However, based on experience from more complex models, we believe that the chosen structure is well suited, and we rather focus on explaining the lack of conformity by estimating 1) possible unmodeled $\mathrm{AlF}_{3}$ addition and 2) possible energy disturbances. This is an intuitive approach since the most important disturbances can be represented by equivalent variations in these two quantities. As examples, we neglect the interaction with the $\mathrm{AlF}_{3}$ rich crust, and we assume constant current efficiency. The conditions for this latter assumption are definitely poor in the period between day 17 and 25 . However, this could be verified through estimation 2 ).

\section{Estimation of $\mathrm{AlF}_{3}$ and energy disturbances}

Based on the experience from the validation in the previous sections, we use analyzed excess $\mathrm{AlF}_{3}$ data to estimate possible $\mathrm{AlF}_{3}$ disturbances through two different case studies. The result is presented in Sec. A. Moreover, in Sec. B, we use measured bath temperature data to estimate possible energy disturbances. Since the $\mathrm{AlF}_{3}$ and the energy balance are exposed to several different disturbances, the estimated disturbances 


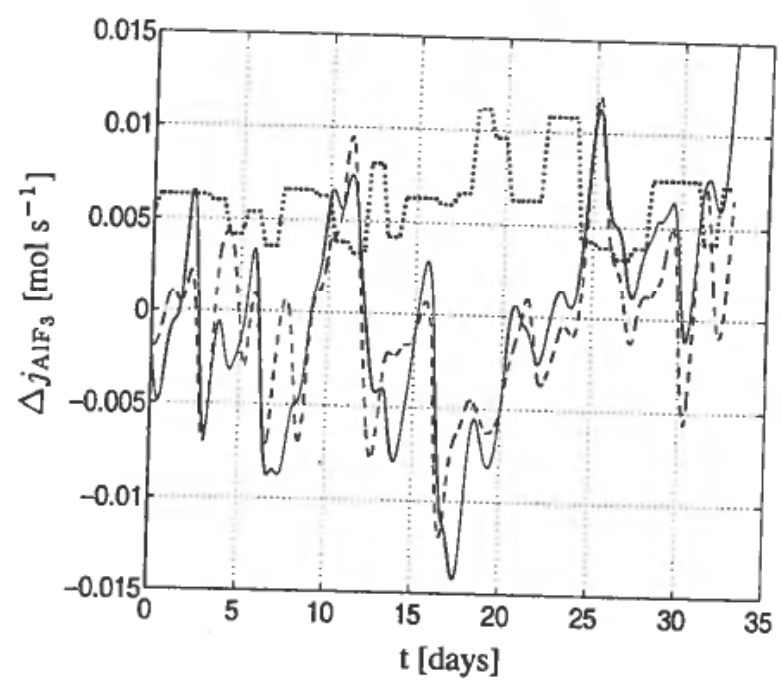

Figure 16. Estimated equivalent $\mathrm{AlF}_{3}$ disturbance. Solid line: Case $2 \mathbf{a}$, using varying heat loss. Dashed line: Case $2 \mathrm{~b}$, using constant heat loss. Dotted line: The registered input given in Fig. 11.

are the equivalent disturbances, i.e. we do not address the source, but rather the level of the disturbances. The estimations are performed over a period of 33 days. In Sec. $\mathrm{C}$ we will discuss and compare the results from Secs. A. and B.

\section{A. Estimating equivalent $\mathrm{AlF}_{3}$ disturbance}

The estimation presented in this section is termed Case 2, and similar as for Case 1, we use varying heat loss (Case 2a) and constant heat loss (Case 2b). The estimated equivalent $\mathrm{AlF}_{3}$ is based on the following relationship

$$
\Delta j_{\mathrm{AlF}_{3}}=K_{\mathrm{AIF}_{3}}\left(x_{\mathrm{AIF}_{3} \text {,anaiyzed }}-x_{\mathrm{AlF}_{3} \text {, simulated }}\right) \text {, }
$$

and is shown in Fig. 16. The curve has been lowpass filtered to emphasize the main variations. We have also indicated the registered $\mathrm{AlF}_{3}$ input in the same figure. The equivalent $\mathrm{AlF}_{3}$ evaporation is held constant at an average rate corresponding to the average input rate of $\mathrm{AlF}_{3}$, given in Fig. 11 .

The corresponding bath temperature responses are shown in Fig. 17. We see that using constant heat loss, we get a relatively good correspondence to measured temperature. It should be mentioned that, due to the estimated equivalent in Fig. 16, the excess $\mathrm{AlF}_{3}$ shows very good conformity with analyzed values for both Case 2a and $2 \mathbf{b}$ (not shown). In these simulations, positive values of $\Delta j_{\mathrm{AlF}_{3}}$ is regarded as solid $\mathrm{AlF}_{3}$ additions, while negative values is regarded as gaseous equivalent $\mathrm{AlF}_{3}$ evaporating from the bath. However, the impact on the bath temperature of changing the negative values from gaseous to solid $\mathrm{AlF}_{3}$ is negligible. This is due to the small amounts involved compared to e.g. $\mathrm{Al}_{2} \mathrm{O}_{3}$ additions.

It is interesting to note that even if the estimated equivalent $\mathrm{AlF}_{3}$ for Case 2a and $\mathbf{2 b}$ shows similar variations, the bath temperature responses are very different. This is mainly due to the different heat loss models used in these simulations, see Fig. 18. 


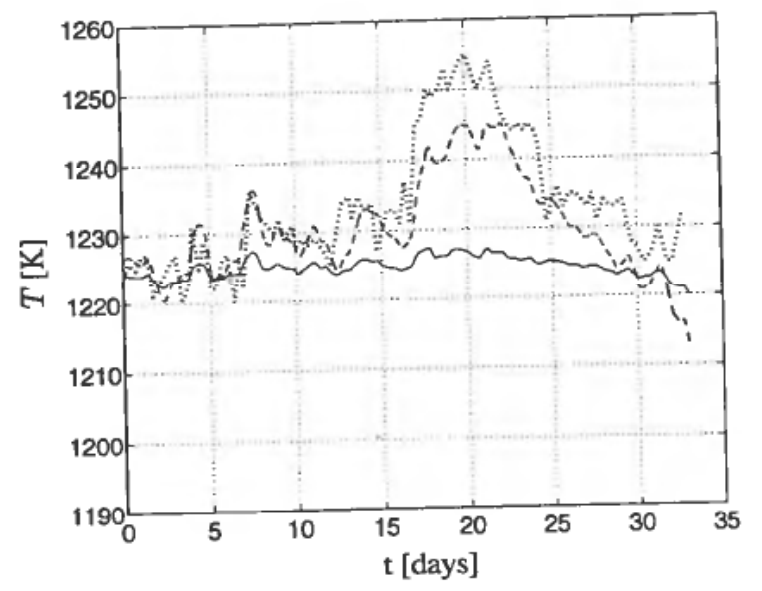

Figure 17. Bath temperature. Solid line: Case 2a, using varying heat loss. Dashed line: Case 2b, using constant heat loss. Dotted line: Measured value.

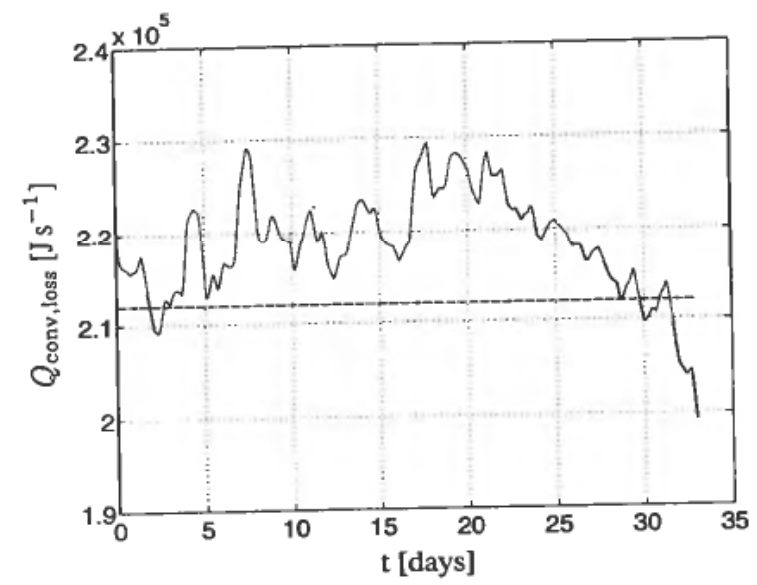

Figure 18. Heat loss from bath to surroundings. Solid line: Case 2a. using varying heat loss. Dashed line: Case $\mathbf{2 b}$, using constant heat loss.

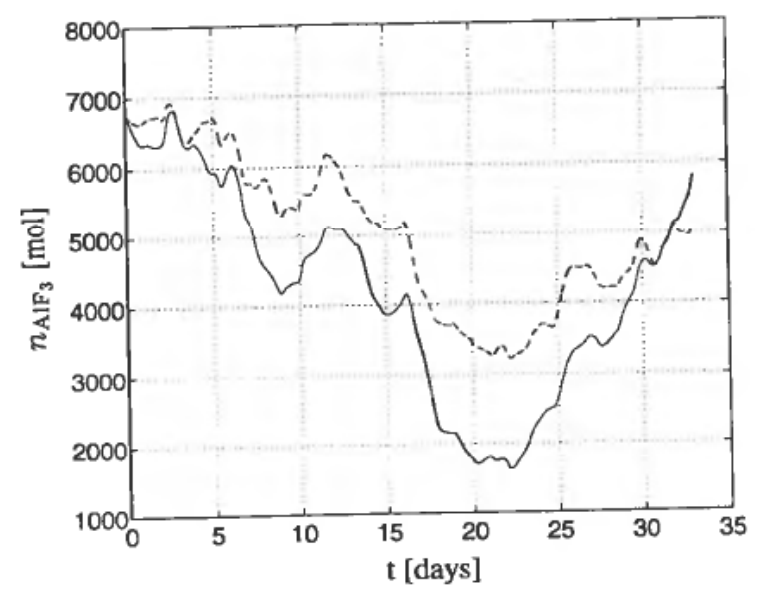

Figure 19. Number of moles $\mathrm{AlF}_{3}$. Solid line: Case 2a, using varying heat loss. Dashed line: Case 2b, using constant heat loss. 


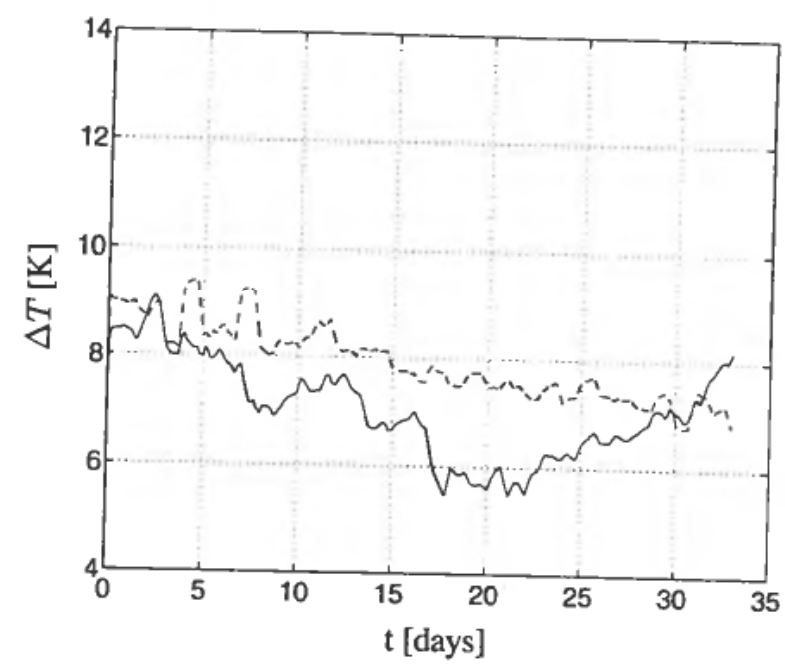

Figure 20. Calculated superheat. Solid line: Case 2a, using varying heat loss. Dashed line: Case $2 \mathbf{b}$, using constant heat loss.

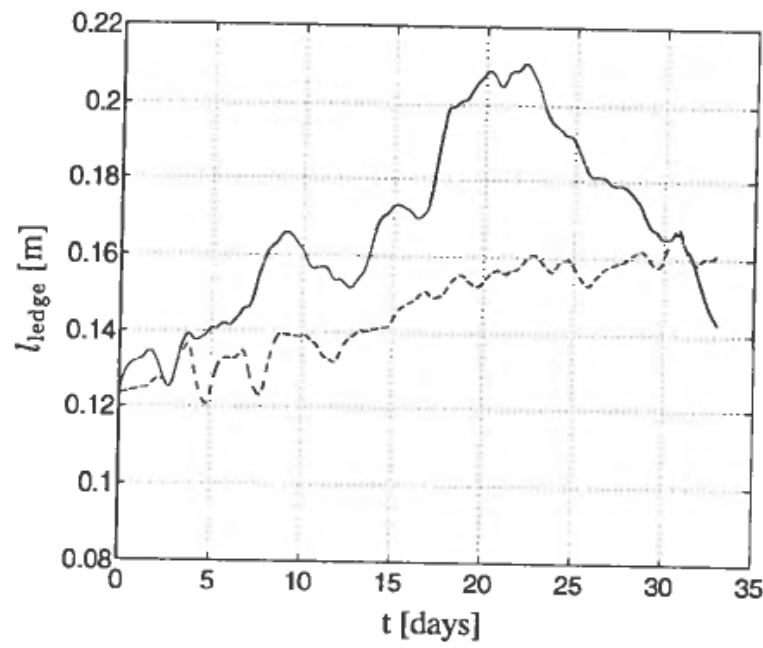

Figure 21. Side ledge thickness. Solid line: Case 2a. using varying heat loss. Dashed line: Case 2b, using constant heat loss.

In addition to the above simulation results, there are other variables of interest that reveal information about the cell state not shown in the bath temperature and excess $\mathrm{AlF}_{3}$ responses. Such variables are the number of moles $\mathrm{AlF}_{3}$ in the bath, superheat, side ledge thickness and mass fraction of $\mathrm{CaF}_{2}$. These are presented in Figs. 19 to 22 .

\section{B. Estimating equivalent energy disturbance}

The estimation presented here is termed Case 3. The estimated equivalent energy disturbance is based on the following relationship

$$
\Delta Q=K_{Q}\left(T_{\text {bath,measured }}-T_{\text {bath,simulater }}\right),
$$




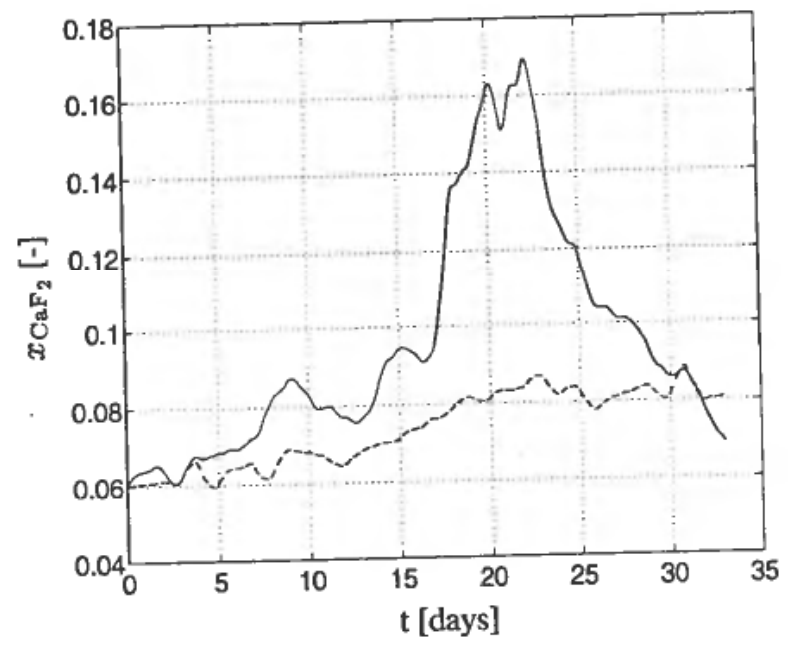

Figure 22. Mass fraction of $\mathrm{CaF}_{2}$. Solid line: Case 2a, using varying heat loss. Dashed line: Case $2 b$, using constant heat loss.

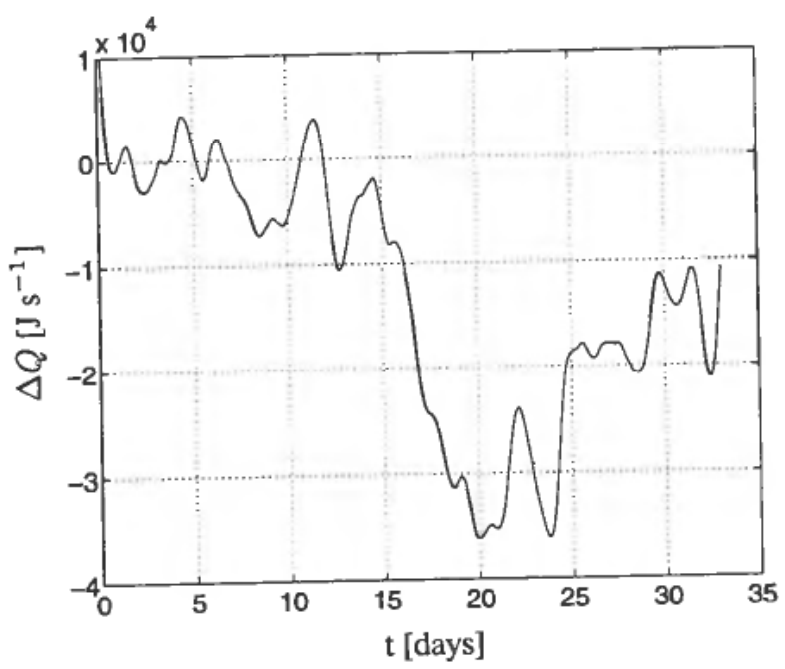

Figure 23. Estimated equivalent energy disturbance for Case 3.

and is shown in Fig. 23. The curve has been lowpass filtered to emphasize the main variations. Note that this heat loss, $\Delta Q$, comes in addition to a constant heat loss of $212 \mathrm{~kJ} \mathrm{~s}^{-1}$. As mentioned earlier, this constant heat loss comprises the heat loss from bath to both metal and surroundings. If we assume that the variations in Fig. 23 are caused by variations in the heat loss from bath to surroundings only, the magnitude of the variation is less than $\pm 10 \%$ of the mean value. The bath temperature (not shown) shows a very good conformity with measured values.

The corresponding excess $\mathrm{AlF}_{3}$ response is given in Fig. 24, and it shows good conformity with the analyzed value. It should be noted, however, that the simulation result is strongly dependent on the initial amount of bath. If the initial amount is too large, the dilution effect that causes the excess $\mathrm{AlF}_{3}$ to change, will be less than shown 


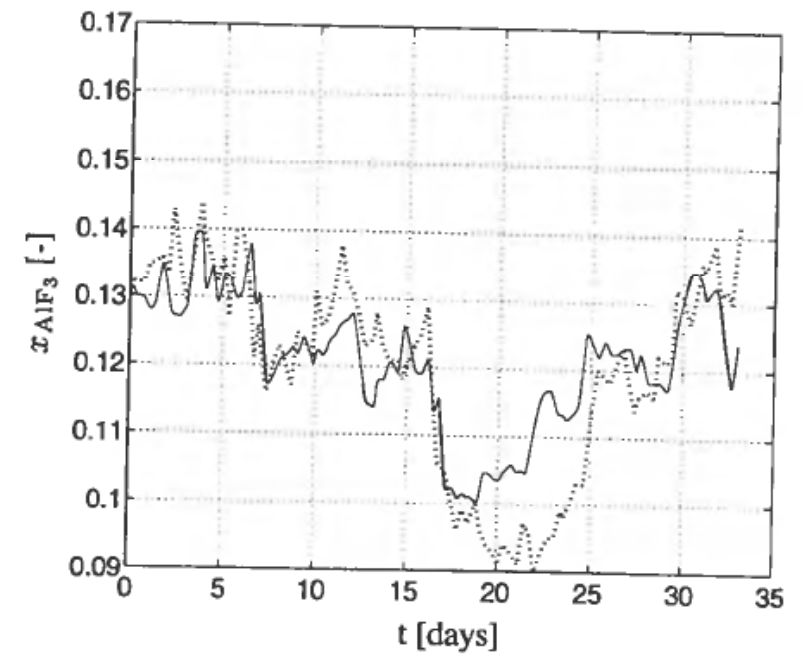

Figure 24. Excess $\mathrm{AlF}_{3}$. Solid line: Case 3, estimated equivalent energy disturbance. Dotted line: Analyzed value.

in Fig. 24. Moreover, the equivalent evaporation of $\mathrm{AlF}_{3}$ is held constant equal to the average input rate as for Case 2. This is, however, not necessarily the best model, and it is believed that the fluoride evaporation is higher at higher temperatures. This would have improved the simulation result in Fig. 24 for the period between 17 and 25 days.

The number of moles $\mathrm{AlF}_{3}$ in the bath, the superheat, the side ledge thickness and the mass fraction of $\mathrm{CaF}_{2}$ are shown in Figs. 25 to 28 .

\section{Discussion}

In discussing the results presented above, it is important to be aware of the assumptions made during the model development phase, and have these in mind when comparing and interpreting the results.

Due to the rather good conformity of both bath temperature and excess $\mathrm{AlF}_{3}$ in Case

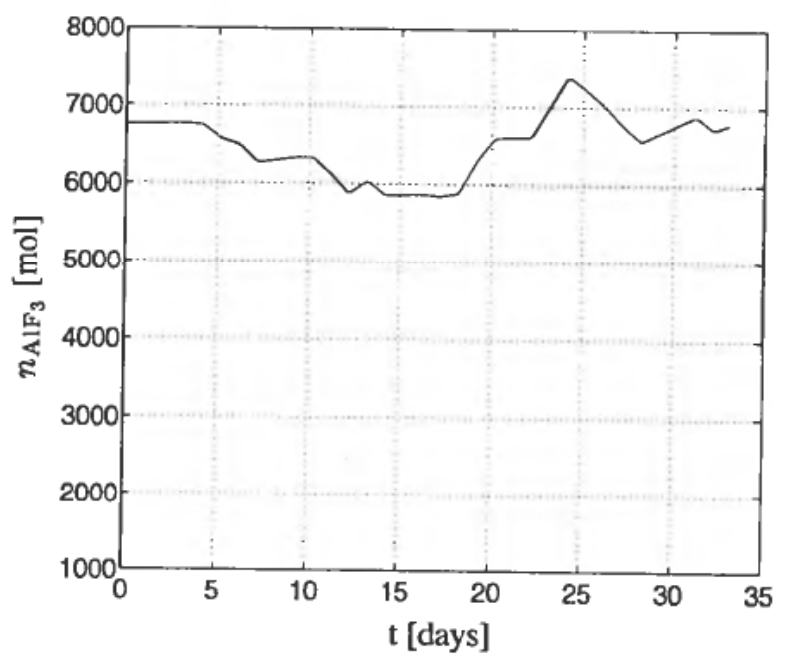

Figure 25. Number of moles $\mathrm{AlF}_{3}$ for Case 3 . 


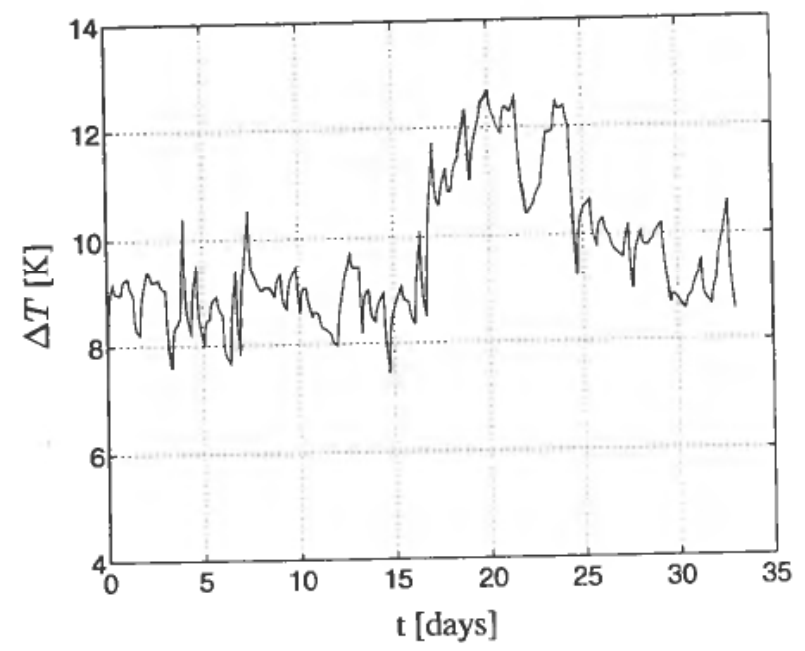

Figure 26. Calculated superheat for Case 3.

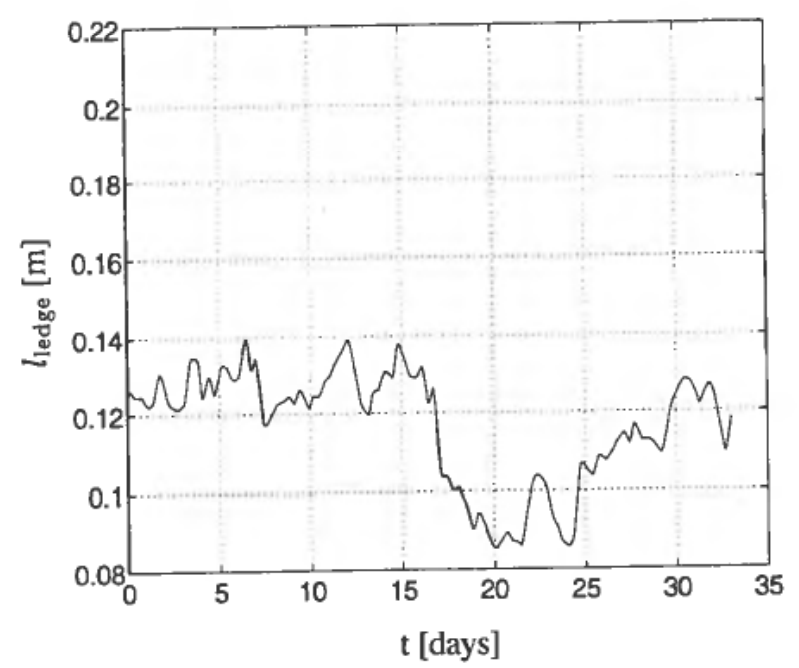

Figure 27. Side ledge thickness for Case 3.

2b and in Case 3, we have to use other cell variables in order to determine which case study most likely explains the observed cell behavior. These cell variables are verified against knowledge of how the cell behaves. For this data set, the period between day 17 and day 25 should be applicable to use as verification due to large variations in temperature and excess $\mathrm{AlF}_{3}$.

Generally, the mass fraction of $\mathrm{CaF}_{2}$ is expected to vary by a fraction of \pm 0.005 or less. Moreover, the side ledge is believed to melt at increased temperatures, and hence, result in reduced side ledge thickness. This is due to increased superheat. If we compare the results from Case $\mathbf{2}$ and $\mathbf{3}$ with the expected behavior of these three variables $\left(x_{\mathrm{CaF}_{2}}, l_{\text {ledge }}\right.$ and $\left.\Delta T\right)$, we see that Case 3 seems to give more reasonable results than Case 2b. Moreover, we can discard the results obtained from Case 2a. 


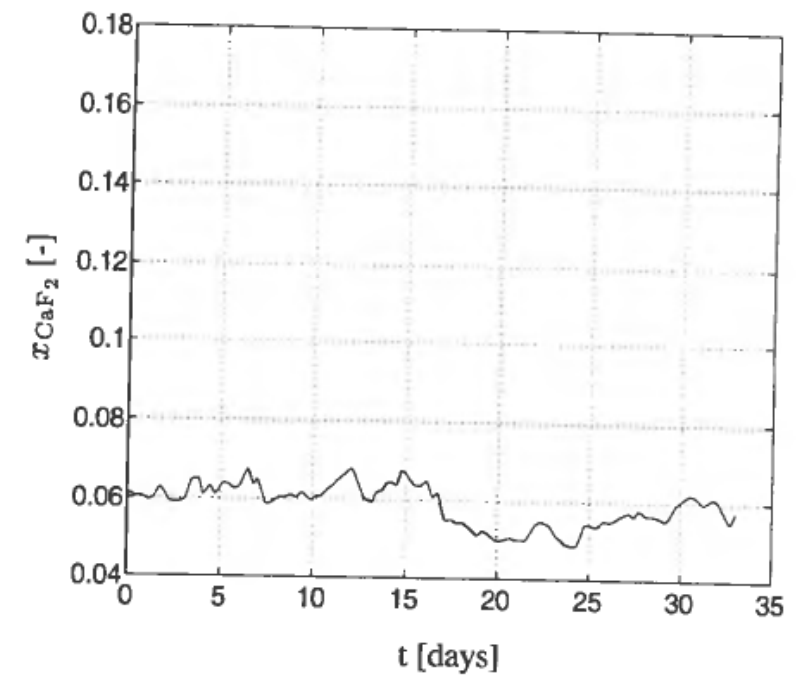

Figure 28. Mass fraction of $\mathrm{CaF}_{2}$ for Case 3 .

If we use the estimated equivalents in Figs. 16 and 23 as means for comparing the case studies, we see that for Case $\mathbf{2 b}$ the model reacts with a very high loss in $\mathrm{AlF}_{3}$ to explain the increased temperature at 17 days. This is also seen from Fig. 19. Possible explanations to the large variations in estimated $\mathrm{AlF}_{3}$ equivalent are varying content of fluoride and sodium in the secondary alumina from dry cleaning, wrong scoop size used in the model, deformation of $\mathrm{AlF}_{3}$ rich crust falling into the bath, or variations in sodium consumption of the cathode. Due to the size of the variations, it is however, not likely that these factors can explain the overall disturbances alone. On the other hand, if a sludge phase of $\mathrm{AlF}_{3}$ is believed to have large impact on the cell behavior, parts of the estimated disturbances could indirectly visualize the internal flow of $\mathrm{AlF}_{3}$ between the bath and the sludge.

For Case 3, the corresponding explanation in Fig. 23 to the increased temperature at 17 days, is a decreased heat loss of approximately $30 \mathrm{~kJ} \mathrm{~s}^{-1}$. The variation in the estimated energy disturbance is $\pm 20 \mathrm{~kJ} \mathrm{~s}^{-1}$ (or only $\pm 10 \%$ with respect to the mean value) and possible explanations could be combinations of varying crust thickness, varying current efficiency and cell operation. If we assume that the variations are caused by changes in current efficiency only, the variation would be $\Delta \mathscr{C} \mathscr{E}= \pm 8 \%$ for a $160 \mathrm{kA}$ cell. This is, of course, too large variations for a specific cell. However, in the period between day 15 and 25, the conditions are poor for high current efficiencies, and this could explain a significant part of the variations found in Fig. 23.

Note also that for Case $2 \mathbf{b}$ the amount of $\mathrm{AlF}_{3}$ in the bath is reduced to the half of the initial amount during the simulation. Case 3 and Fig. 25, on the other hand, shows that even if the amount of $\mathrm{AlF}_{3}$ has small variations, the simulated excess $\mathrm{AlF}_{3}$ shows good conformity in Fig. 24. This is due to the dilution effect of melting side ledge as shown in Fig. 27.

\section{A novel control strategy}

The results summarized and discussed above are of vital importance to the control of the excess $\mathrm{AlF}_{3}$ and the bath temperature of an electrolysis cell. To the authors' knowledge, all control strategies implemented in the industry use $\mathrm{AlF}_{3}$ addition as the 
main control variable to keep the excess $\mathrm{AlF}_{3}$ and temperature close to target values (see, e.g. [2] and [7]). Adjustments of the energy input, or the reference resistance, is mainly used to manipulate the energy balance such that the bath temperature on average is within acceptable values when the average excess $\mathrm{AlF}_{3}$ is close to a predefined value.

This common control strategy seems intuitively appealing since $\mathrm{AlF}_{3}$ additions are used to increase the excess $\mathrm{AlF}_{3}$ and frequent adjustments of the anode beam is avoided. Large and frequent anode beam adjustments result in crust deformation, and consequently disturbances in both mass and energy balances, and is traditionally considered to result in poor cell performance. On the other hand, these disturbances are small compared to the estimated $\mathrm{AlF}_{3}$ and energy adjustments shown in Figs. 16 and 23.

\section{A. Possible explanations of observed cell behavior}

From Fig. 16 it can be concluded that large $\mathrm{AlF}_{3}$ additions should be avoided even when the excess $\mathrm{AlF}_{3}$ is low. The reasons is that the total amount of $\mathrm{AlF}_{3}$ in the cell does not change substantially from one day to the next. This means that a lack of $\mathrm{AlF}_{3}$ is not the main reason why the excess $\mathrm{AlF}_{3}$ in some cases suddenly decreases. If large amounts of $\mathrm{AlF}_{3}$ is added to compensate for a sudden and large reduction, the excess $\mathrm{AlF}_{3}$ will attain very high values when the underlying cause for the excess $\mathrm{AlF}_{3}$ reduction is resolved. This is also seen from the model validation in Sec. V-B, Fig. 8. The temperature drop caused by the $\mathrm{AlF}_{3}$ addition is small compared to the drop caused by energy manipulations.

Results presented in this paper demonstrate that disturbances in the energy balance is the main reason for variations in the excess $\mathrm{AlF}_{3}$ and the bath temperature. Using this as the basic hypothesis, the following discussion illustrates why there seems to be a time-lag between $\mathrm{AlF}_{3}$ additions and corresponding responses in the excess $\mathrm{AlF}_{3}$, and why extensive use of $\mathrm{AlF}_{3}$ additions to reduce the variations will reinforce long-term variations. The time constants of the dominating variations are in the order of days. When the excess $\mathrm{AlF}_{3}$ decreases due to a disturbance in the energy balance, increased $\mathrm{AlF}_{3}$ additions will initially just compensate for the negative trend and will not result in increased excess $\mathrm{AlF}_{3}$. Large amounts of $\mathrm{AlF}_{3}$ will, however, result in higher excess $\mathrm{AlF}_{3}$ values. But the full effect of the additions will become apparent when the energy disturbance is resolved. Then the excess $\mathrm{AlF}_{3}$ will become too high, and actions are needed to reduce it. Due to variations in the side ledge thickness and continuous disturbances in the energy balance, it is not straightforward to obtain the desired excess $\mathrm{AlF}_{3}$ and at the same time make sure that the $\mathrm{AlF}_{3}$ additions in average equal the mean $\mathrm{AlF}_{3}$ consumption (evaporation and sodium penetration in the cathode). Consequently oscillations result.

\section{B. Brief description of the proposed control strategy}

The obtained results demonstrate that optimal control of the excess $\mathrm{AlF}_{3}$ and the bath temperature is obtained by using an almost constant $\mathrm{AlF}_{3}$ input and use the energy input to compensate for the disturbances. By optimal control we here mean the control strategy that minimizes bath temperature and excess $\mathrm{AlF}_{3}$ variations. Some adjustments of the $\mathrm{AIF}_{3}$ input, that is integral action, is of course needed to compensate for the cell aging, evaporation and changes in the alumina quality. The $\mathrm{AlF}_{3}$ input adjustments should be based on a simple mass balance to make sure that the average addition is close to the average consumption and thereby avoiding the long-term variations. Moreover, 
$\mathrm{AlF}_{3}$ may be used to treat non-conformities such as very high temperatures. Then operational consistency in the treatment of the non-conformities is of vital importance to reduce the variations that usually will result when the non-conformity is resolved. Operational consistency is important because the time-constants and the number of people involved are large.

In many cell-lines the energy input is squeezed to a minimum. A further reduction of the resistance reference, or the anode-cathode distance, will result in reduced current efficiency. As a result, the net energy input to the energy balance will increase. Consequently, only elevation of resistance reference is used in present control schemes. However, active use of both positive and negative changes in the resistance reference requires that the resistance reference can be decreased without resulting in an increased energy input on average. It is therefore suggested that the resistance reference is increased, if needed, to allow for temporary reductions in the energy input to compensate for high temperature and low excess $\mathrm{AlF}_{3}$. This approach introduces an additional degree of freedom not used in present controllers. An additional approach for manipulating the energy balance directly is to use the crust thickness as a control input. By carefully covering and monitoring the crust, the long-term variations in heat loss can be controlled. However, this is not as powerful and immediate as anode beam movements.

To summarize, $\mathrm{AlF}_{3}$ additions should be used when the temperature is within normal range and the excess $\mathrm{AlF}_{3}$ is low. Moreover, positive and negative energy manipulations should be used when both temperature and excess $\mathrm{AlF}_{3}$ are outside target values.

\section{Consequences of the proposed control strategy}

The proposed control strategy has impact on both energy and mass consumption. Even if we suggest to keep the mean resistance reference above the minimum in order to introduce an additional degree of freedom in the controller, it is important to note that we can still obtain energy savings. This is achieved by keeping the resistance reference lower than the average value in present control schemes, which is larger than the reference set point.

If we manage to achieve stable cell condition, it is favorable to the current efficiency. The effects of improved current efficiency are increased economic turnover, reduced energy consumption and hence, less energy available to loose as heat. This latter effect, necessary to maintain the energy balance of the cell, could be compensated by increased current through the cell or increased anode-cathode distance. This again improves the proposed control strategy.

Other profitable side effects of stable cell conditions are prolonging of cell life and reduced need for expensive $\mathrm{AlF}_{3}$ and $\mathrm{Na}_{2} \mathrm{CO}_{3}$ additions used to reach target values for excess $\mathrm{AlF}_{3}$.

\section{Superheat as a parameter for control}

From laboratory experiments, it is found that the superheat has a large impact on e.g. $\mathrm{Al}_{2} \mathrm{O}_{3}$ dissolution. If we assume that the superheat also affects the dissolution of $\mathrm{AlF}_{3}$, we would like to investigate how the superheat changes during normal operation, i.e. at irregular over and under feeding of $\mathrm{Al}_{2} \mathrm{O}_{3}$. For the simulation shown in Figs. 29 and 30 , the period for the over and under feeding is 3 hours. 3 hours is of course an extreme value, but it is used to illustrate the dynamics. The results obtained with shorter periods can to some extent be seen directly from Fig. 30 . 


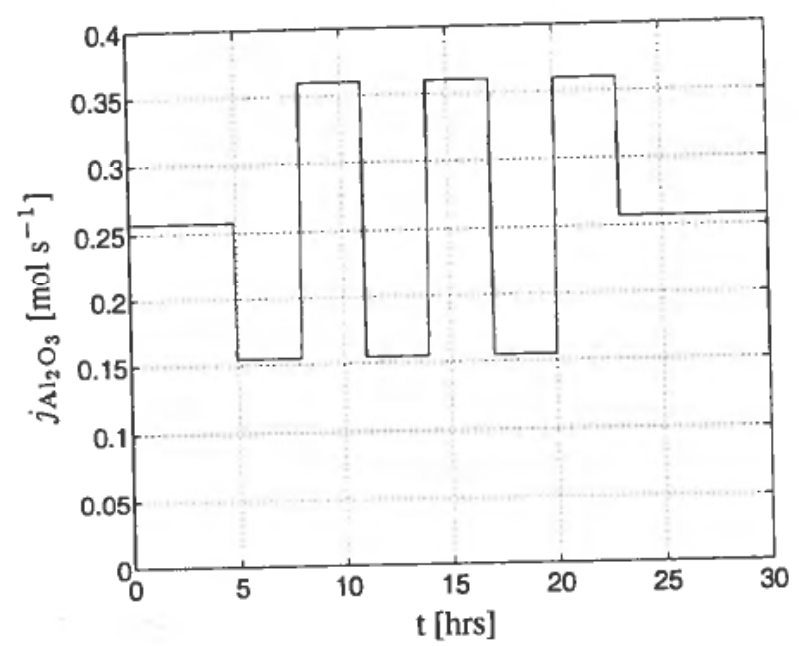

Figure 29. $\mathrm{Al}_{2} \mathrm{O}_{3}$ addition during normal operation. Note that a rate of $0 \cdot 1 \mathrm{~mol} \mathrm{~s}^{-1}$ is equivalent to $800 \mathrm{~kg} \mathrm{day}^{-1}$.

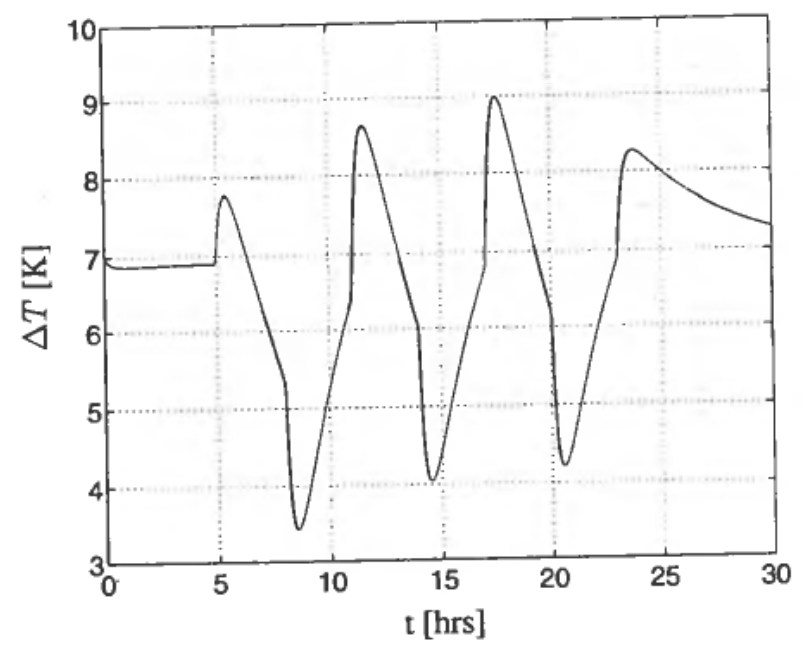

Figure 30. Superheat during normal operation.

We see that superheat first have a maximum and then decreases during the low feeding period. This is very important to take into consideration if the $\mathrm{AlF}_{3}$ feeding strategy is to take the always changing alumina feeding into account. The cause of this behavior is that the liquidus temperature increases faster than the bath temperature during the low feeding periods. This can be verified from the industrial data plotted in Figs. 31 and 32. The superheat in Fig. 32 is calculated from filtered bath temperature measurement and analyzes of $x_{\mathrm{Al}_{2} \mathrm{O}_{3}}$ and excess $\mathrm{AlF}_{3}$.

We see that over a low feeding period of 6 hours, the superheat has a drop of $3 \mathrm{~K}$. The resistive energy generated in the bath, $Q_{\text {input }}$, was relatively constant in this period. 


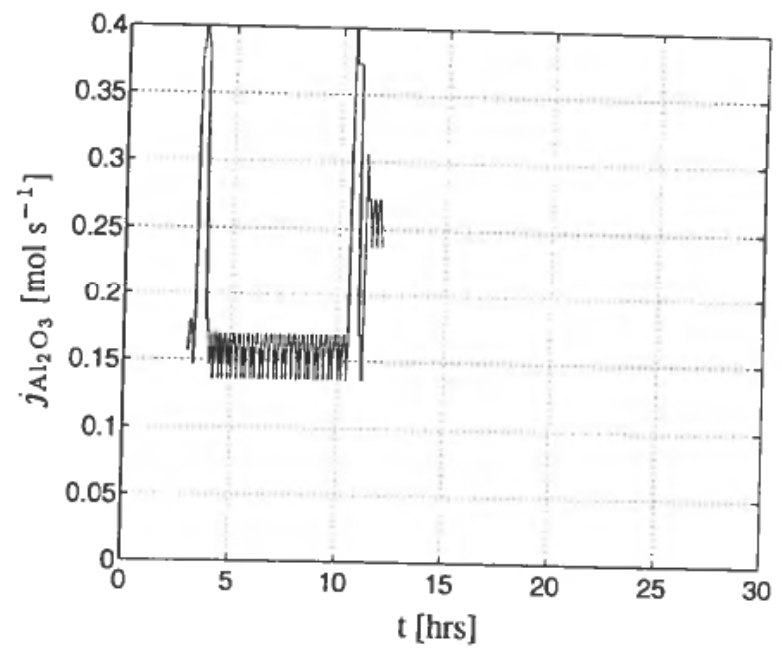

Figure 31. Registered $\mathrm{Al}_{2} \mathrm{O}_{3}$ addition.

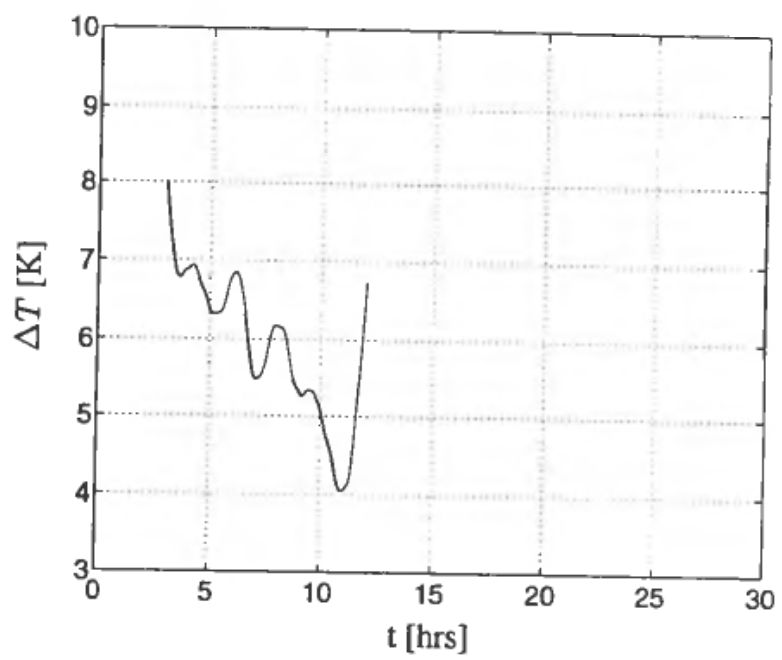

Figure 32. Superheat based on bath temperature measurement using $\mathrm{AlF}_{3}$ and $\mathrm{Al}_{2} \mathrm{O}_{3}$ analyzes.

\section{Conclusions}

Data analyzes and dynamic simulations have shown that unknown dynamics or disturbances in the energy balance are the main sources for the rather large variations in excess $\mathrm{AlF}_{3}$ and bath temperature which are present in most cell lines in the industry. The obtained results demonstrate that optimal control of the excess $\mathrm{AlF}_{3}$ and the bath temperature is obtained by using an almost constant $\mathrm{AIF}_{3}$ input and use the energy input to compensate for the disturbances. The $\mathrm{AlF}_{3}$ input adjustments needed to obtain an excess $\mathrm{AlF}_{3}$ close to target value should be based on a simple mass balance to make sure that the average addition is close to the average consumption without introducing long-term variations in the excess $\mathrm{AlF}_{3}$. 
Table 1. Symbols defined in the topological part of the graphical representation scheme

\begin{tabular}{|c|c|c|}
\hline & elementary & composite \\
\hline device & $\begin{array}{l}\text { phase } \\
\text { source/sink } \\
\text { controller }\end{array}$ & \\
\hline connection & $\begin{array}{ll}\text { phase } & \\
\text { boundary } & \\
\text { signal } \\
\text { connection }\end{array}$ & \\
\hline
\end{tabular}

Table 2. Relations for topological components

\begin{tabular}{|ll|}
\hline \multicolumn{2}{|c|}{ relations } \\
\hline relation \\
element & $\bigcirc$ \\
signal line & $\longrightarrow$ \\
component & \\
connecting line & $=$ \\
\hline
\end{tabular}

The presented results are based on a rather simple dynamic model and a limited number of data sets from industrial cells. However, the simulations summarize results and experience obtained through extensive simulations on different models based on different model assumptions.

\section{APPENDIX}

The modeling methodology employed here is based on a formal graphical representation scheme described in [12]. This scheme consists of two main parts, a topological and a phenomenological part. To the topological part belongs the decomposition of the process into modules representing control volumes (devices) having accumulation properties, and boundaries (connections) involving some kind of flow between devices.

The phenomenological part describes the phenomena taking place inside the topological process components, e.g. chemical reaction or conductive heat flow. Hence, we focus on the development of analytical or first principles mathematical models.

\section{A. Topological process abstraction}

Topological process abstraction is the abstraction or decomposition of a system into a network of topology components, i.e. devices and connections, at several different abstraction levels. In order to separate the components at these different levels, we have 
On the $\mathrm{AlF}_{3}$ and temperature control of an aluminum electrolysis cell

Table 3. Symbols defined in the phenomenological part of the graphical representation scheme

\begin{tabular}{|c|c|c|c|}
\hline & $\begin{array}{r}\text { ACCU- } \\
\text { MULATION }\end{array}$ & TRANSPORT & REACTION \\
\hline 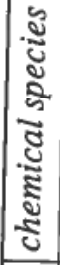 & $\begin{array}{l}\text { gas } \\
\text { liquid } \square\end{array}$ & $\begin{array}{l}\text { diffusion }- \\
\text { convection } \rightarrow\end{array}$ & $\begin{array}{ll}\text { surface } & R^{\prime \prime} \\
\text { volume } & R^{\prime \prime \prime \prime}\end{array}$ \\
\hline \multirow[b]{2}{*}{ Еँ } & \multirow[b]{2}{*}{$\triangle$} & \multirow{2}{*}{$\begin{array}{c}\text { conduction } \triangle \\
\text { convection } \\
\text { radiation }\end{array}$} & GENERATION \\
\hline & & & $\begin{array}{l}\text { electrical } \Omega \\
\text { mechanical }\end{array}$ \\
\hline
\end{tabular}

Table 4. Relations for phenomenological components

\begin{tabular}{|lc|}
\hline \multicolumn{2}{|c|}{ relations } \\
\hline material & \\
flow & \\
energy & $\ddots$ \\
flow & $\ddots$ \\
\hline
\end{tabular}

composite and elementary components. Composite topology components are components containing a set of composite and/or elementary topology components, though, at the lowest level composed of elementary devices and connections. Only the elementary topology components contain a phenomenological description.

The basis for topological decomposition of plant processes is often guided by the physically separated unit processes constituting the plant. For the modularization of unit processes themselves, there is no similar approach. The basis may vary from chemical phase to temperature zone modularization within the same model, depending on the process and the scope of the model. The approach employed in [12] is to choose chemical phase as a modularization basis.

The graphical symbols for elementary and composite components are given in Table 1. In order to connect the topology components into a complete network, we employ the various links given in Table 2 . The component connecting line is used between the topological components, and the relation element is used to indicate relations to higher levels of abstraction. In order to visualize the topological part of the model, we use a process topology diagram (PTD).

\section{B. Phenomenological process abstraction}

Phenomenological process abstraction is the abstraction of the behavior of elementary topological components into a network of phenomenological components. 
The identification of these components is based on three process characteristics, i.e. TRANSPORT, REACTION/GENERATION and ACCUMULATION. These characteristics are related to the following extensive quantities, mass and energy. The quantity mass is the mass of each chemical species. For these characteristics and quantities we have the symbols given in Table 3.

As for the topological components, we need relations as connecting elements between the phenomenological symbols. These are given in Table 4 . The direction of the arrows in Table 4 is not an indication of the direction of the flow, but rather it defines the positive direction for the flow.

A transport, reaction and accumulation (TRAV) is used to construct the network of phenomenological symbols.

\section{ACKNOWLEDGEMENTS}

This work was financially sponsored by Hydro Aluminium AS and the Research Council of Norway through the Expomat and Prosmat programs. Moreover, the authors would also like to thank Hydro Aluminium AS for providing cell data.

\section{REFERENCES}

[1] GRJOTHEIM, K. and KVANDE, H., eds. (1993). Introduction to aluminium electrolysisUnderstanding the Hall-Héroult Process, Aluminium-Verlag, 2nd ed. (Düsseldorf, Germany).

[2] ENTNER, P. M. (1992). Control of $\mathrm{AlF}_{3}$ concentration. Light Metals 1992, pp. 369-374.

[3] ENTNER, P. M. (1993). Further development of the $\mathrm{AlF}_{3}$-model. Light Metals 1993, pp. $265-268$.

[4] ENTNER, P. M. (1995). Control of bath temperature. Light Metals 1995, pp. 227-230.

[5] ENTNER, P. M. and GUDMUNDSSON, G. A. (1996). Further development of the temperature model. Light Metals 1996, pp. 445-449.

[6] DesclauX, P. (1987). $\mathrm{AlF}_{3}$ additions based on bath temperature measurements. Light Metals 1987, pp. 309-313.

[7] WILSON, M. J. (1992). Practical considerations used in the development of a method for calculating aluminium fluoride additions based on cell temperatures. Light Metals 1992. pp. $375-378$.

[8] Peyneau, J. M. (1988). The automated control of bath composition on high amperage cell. In Proc. of International Symposium on Reduction and Casting of Aluminium (Montreal, Canada), pp. 189-195.

[9] TAYLOR, M. P. (1992). Fluoride material balance. In Fourth Australian Aluminium Smelter Technology Workshop (Sydney, Australia), pp. 720-732.

[10] TABSH, I., DuPUIS, M. and GOMES, A. (1996). Process simulation of aluminium reduction cells. Light Metals 1996, pp. 451-457.

[11] WASB $\varnothing$, S. O. (1996). Ferromanganese Furnace Modeling using Object Oriented Principles. Dr. ing. thesis, Department of Engineering Cybernetics, Norwegian University of Science and Technology (NTNU), Trondheim, Norway.

[12] Drengstig, T., WASB $\emptyset$, S. O. and Foss, B. A. (1997). A formal graphical based process modeling methodology. Comput. Chem. Engng., vol. 21, pp. S835-S840.

[13] SOLL, P., HAARBERG, T., EgGEN, T., SKYBAKMOEN, E. and STERTEN, A. (1994). A laboratory study of current efficiency in cryolitic melts. Light Metals 1994, pp. 195-203.

[14] HAUPIN, W. and KVANDE, H. (1993). Mathematical model of fluoride evolution from Hall-Hèroult cells. Light Metals 1993, pp. 257-263.

[15] THE MATHWORKS, INC. (1992). Matlab, User's and Reference Guide.

[16] THE MATHWORKS, INC. (1992). Simulink, User's and Reference Guide.

[17] Chase, M. W., Davies, C. A., Downey, J. R., Frurip, D. J., McDonald, R. A. and SYVERUD, A. N. (1985). JANAF Thermochemical Tables, 3rd ed. The American Chemical Society and the American Institute of Physics for the National Bureau of Standards. 
On the $\mathrm{AlF}_{3}$ and temperature control of an aluminum electrolysis cell

Nomenclature

t time

$x$ weight fraction

$j$ molar flow

$r$ molar generation/consumption

$\Delta j$ estimated equivalent mass disturbance

$n$ number of moles

$R$ resistance

$I$ current

$Q$ energy flow

$\Delta Q$ estimated equivalent energy disturbances

$T$ temperature

$\Delta T$ superheat in bath

$\mathscr{C} \mathscr{E}$ current efficiency

$\triangle \mathscr{C} \mathscr{E}$ change in current efficiency

$\Delta_{\text {fus }} H^{\circ}$ heat of fusion

$\bar{c}_{p}$ average specific heat capacity

$A$ area

$h$ heat transfer coefficient

$l$ length/thickness

$k$ thermal conductivity

$K$ estimation constant

[s]

[-]

[ $\mathrm{mol} \mathrm{s}^{-1}$ ]

$\left[\mathrm{mol} \mathrm{s}^{-1}\right]$

[ $\mathrm{mol} \mathrm{s}^{-1}$ ]

[mol]

[ $\Omega$ ]

[A]

$\left[\mathrm{JS}^{-1}\right]$

$\left[\mathrm{J} \mathrm{s}^{-1}\right]$

[K]

[K]

[-]

[-]

$\left[\mathrm{J} \mathrm{mol}^{-1}\right.$ ]

[J mol ${ }^{-1} \mathrm{~K}^{-1}$ ]

$\left[\mathrm{m}^{2}\right]$

$\left[\mathrm{JK}^{-1} \mathrm{~s}^{-1} \mathrm{~m}^{-2}\right]$

[m]

$\left[\mathrm{JK}^{-1} \mathrm{~s}^{-1} \mathrm{~m}^{-1}\right.$ ] 